\title{
Article \\ Selective adsorption of aqueous diclofenac sodium, naproxen sodium, and ibuprofen using a stable Fe3O4-FeBTC metal or- ganic framework
}

\author{
Aldo A. Castañeda Ramírez ${ }^{1 *}$, Elizabeth Rojas García ${ }^{2}$, Ricardo López Medina ${ }^{3}$, José L. Contreras Larios ${ }^{4}$, Raúl \\ Suárez Parra ${ }^{5}$ and Ana M. Maubert Franco ${ }^{6}$, \\ 1 Química de Materiales, Ciencias Básicas e Ingeniería, Universidad Autónoma Metropolitana-Azcapotzalco, \\ 02200, Mexico City. Mexico. \\ 2 Ingeniería de Procesos e Hidráulica, Ciencias Básicas e Ingeniería, Universidad Autónoma Metropolitana- \\ Iztapalapa, 09340, Mexico City. Mexico. erg@xanum.uam.mx \\ 3 Energía, Ciencias Básicas e Ingeniería, Universidad Autónoma Metropolitana-Azcapotzalco, 02200, Mexico \\ City. Mexico; rilome@correo.azc.uam.mx \\ 4 Energía, Ciencias Básicas e Ingeniería, Universidad Autónoma Metropolitana-Azcapotzalco, 02200, Mexico \\ City. Mexico; jlcl@azc.uam.mx \\ 5 Instituto de Energías Renovables, Universidad Nacional Autónoma de México, 62580, Morelos, México; \\ rsp@ier.unam.mx \\ 6 Química de Materiales, Ciencias Básicas e Ingeniería, Universidad Autónoma Metropolitana-Azcapotzalco, \\ 02200, Mexico City. Mexico; amf@azc.uam.mx \\ - Correspondence: ing.carauam@mail.com +525571203078
}

\begin{abstract}
This work is part of addressing the problem of water contamination with last generation pollutants. To solve this problem, the FeBTC metal organic framework (MOF) incorporated with magnetite is proposed as a novel material. The material was synthesized by the in situ solvothermal method, and $\mathrm{Fe}_{3} \mathrm{O}_{4}$ nanoparticles were added during FeBTC MOF synthesis and used in drug adsorption. The materials were characterized by XRD, FTIR, Raman spectroscopy, and N2-physisorption at $77 \mathrm{~K}$. Pseudo-second-order kinetic and Freundlich models were used to describe the adsorption process, and the thermodynamic study revealed that the adsorption of three drugs was a feasible spontaneous exothermic process. The incorporation of magnetite nanoparticles in the FeBTC considerably increased the adsorption capacity of pristine $\mathrm{FeBTC}_{3} \mathrm{Fe}_{3} \mathrm{O}_{4}-\mathrm{FeBTC}$ material showed a maximum adsorption capacity of $357.1 \mathrm{mg} \mathrm{g}^{-1}$ for diclofenac sodium, $70.9 \mathrm{mg} \mathrm{g}^{-1}$ for naproxen sodium, and $122.9 \mathrm{mg} \mathrm{g}^{-1}$ for ibuprofen. Additionally, hybridization of the FeBTC with magnetite nanoparticles reinforced the most vulnerable part of the MOF, increasing the stability of its thermal and aqueous media. The electrostatic interaction, H-bonding, and interactions in the open-metal sites played vital roles in the drug adsorption. The competition of sites in the adsorption of the multicomponent mixture showed selective adsorption of diclofenac sodium and naproxen sodium. This work shows how superficial modification with a low-surface-area MOF can achieve important results of adsorption of water pollutants - not limited to drugs, but extended to other pollutants such as colorants, heavy metals, chlorides, and fluorides-in addition to showing the preferential adsorption sites by means of Raman spectroscopy.
\end{abstract}

Keywords: metal organic frameworks (MOF); nonsteroidal anti-inflammatory drugs (NSAIDs); FeBTC; magnetite

\section{Introduction}

Many industrial pollutants can be found in wastewater. The industrial sector manufactures different chemical reagents to support factories or supply the market with the necessary nutritional, residential, farming, livestock, pharmaceutical, and personal products. Simultaneously, along with these products, the manufacturing sector generates great 
quantities of chemical waste that go to the air, soil, and water. Sooner or later, most of the pollutants make their way into rivers, lakes, and seas. Moreover, people and animals transform all of those products, generating residual inorganic and organic compounds such as detergents and pharmaceuticals and personal care products (PPCPs) [1]. Indeed, all of these pollutants constitute an important threat to flora and fauna, and public health. For this reason, to supply populations with necessary drinking water, it is imperative to find effective procedures for cleaning wastewater [2]. However, in the case of wastewater contaminated with medicines such as nonsteroidal anti-inflammatory drugs (NSAIDs), the cleaning treatment is complex and expensive due to the high concentrations of drugs [3]. When this wastewater is mixed with inorganic pollutants (cation metals, fluorides, nitrates, and phosphates), the cleaning treatment becomes very difficult [4].

Metal organic frameworks (MOFs) are materials with metal aggregates strongly bound by organic ligands containing potential adsorption sites; this feature generates high porosity, and consequently, a highly specific surface [5]. Ligands are typically didentate, tridentate, or tetradentate organics such as benzene dicarboxylate (BDC) or benzenetricarboxylate (BTC) [6]. FeBTC (iron-benzenetricarboxylate) is an MOF with the molecular formula $\mathrm{C}_{9} \mathrm{H}_{3} \mathrm{FeO}_{6}$, commercially known as Basolite F300. Although its chemical composition is well known, it shows poor crystallinity and its structure is unknown [7]. Efforts to elucidate the structure suggest an octahedral metal cluster formed of iron trimers connected to benzene tricarboxylate ligands. Additionally, this MOF shows unsaturated vertices that interact with water molecules and open metal sites $\left(\mathrm{Fe}^{2+/ 3+}\right)$, high water stability, drug-compatible pore size (2 nm diameter), many structural defects, etc. [8]; based on these characteristics, this material could be an excellent candidate for the adsorption of drugs in water.

PPCPs such as diclofenac sodium (DCF), naproxen sodium (NS), and ibuprofen (IB) (Figure 1) have been studied as contaminants to be removed by MOFs because they are among the most abundant in polluted waters. The MOFs MIL-101 (Cr) and MIL-100 (Fe), studied by Jhung et al. [9], proved to be good candidates to remove naproxen and clofibric acid. By analyzing the pollutant capture process, the authors deduced that electrostatic interaction and stereo porous selectivity dominate the adsorption procedure. Later, Jhung et al. [10] studied the adsorption of the same pollutants on MIL-101-Cr functionalized with acidic $\left(-\mathrm{SO}_{3} \mathrm{H}\right)$ and basic $\left(-\mathrm{NH}_{2}\right)$ groups to determine their influences in the aqueous system.

On the other hand, magnetite has proven to be an excellent candidate for removing pollutants in an aqueous medium [11], in addition to its ability to incorporate quite well with other materials [12-14], increasing not only its adsorption capacity but also its recovery in aqueous medium and thermal stability [15]. Although MOFs incorporated with magnetite have already been studied, few have been applied for the removal of contaminants in aqueous media [12,16]. Giesy et al. [17] reported one of the first works to incorporate magnetite in MOFs using HKUST-1 incorporated with magnetic material to remove colorants from water, showing a clear increase in the removal capacity of methylene blue. Chen et al. [18] used an MIL-100 (Fe) MOF incorporated with magnetite to remove rhodamine B from medium, highlighting the effective reuse of the material, the improvement of the removal capacity of the dye, and the stacking of pi bonds and electrostatic interactions as the main possible interactions. Hou et al. [19] used the Freundlich adsorption model and pseudo-second-order kinetic model to describe the adsorption process of MIL-100 (Fe) with magnetite for use with meloxicam and naproxen. Shortly after, the same research group [20], using the same material, showed that photodegradation of drugs such as diclofenac was possible. 
Although there are several studies using MOFs incorporated with magnetite, most of them are limited to MIL-100 and other MOFs with high specific areas. This study investigated three drugs (ibuprofen, naproxen sodium, and diclofenac sodium) commonly used without a prescription, which makes them the most prevalent and the most important in waste management. In addition, we demonstrate the benefits of an MOF with a surface area of $217 \mathrm{~m}^{2} / \mathrm{g}$ capable of obtaining superior adsorption capacity, showing preferential adsorption sites through Raman and FTIR characterization after the adsorption process.
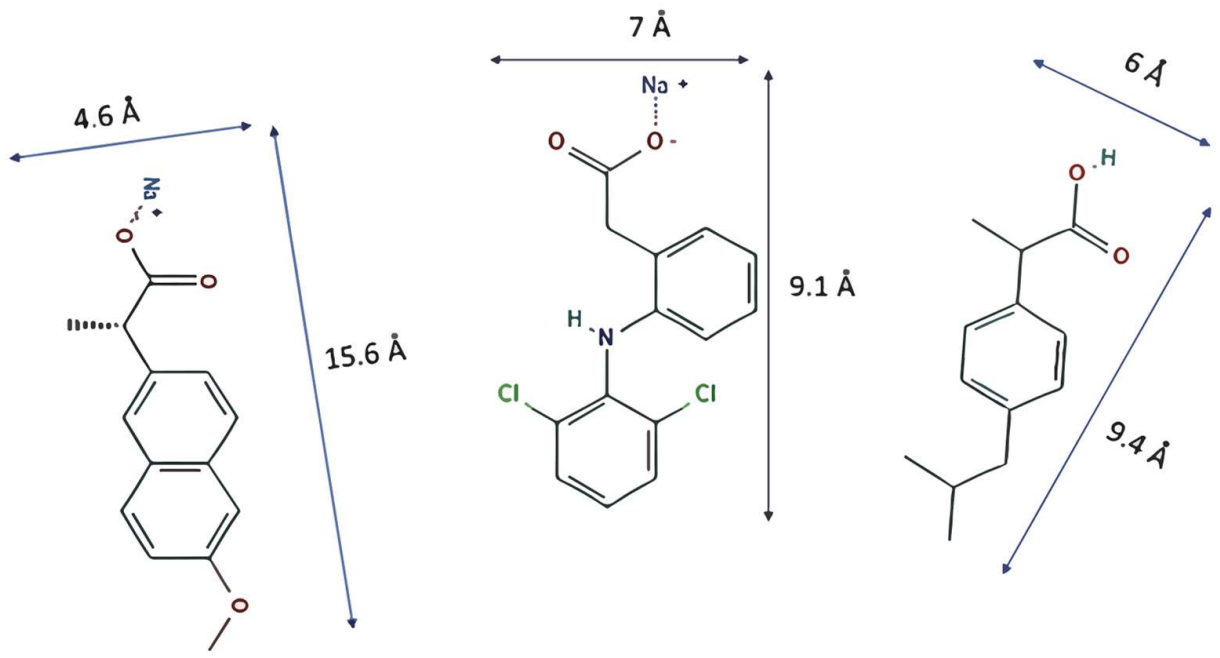

Figure 1. Molecules with their dimensions: naproxen sodium (left), diclofenac sodium (center), and ibuprofen (right).

In the present study, magnetite nanoparticles were proposed as a good interaction material with the FeBTC MOF, because magnetite incorporated into various materials has been shown to improve the capacity to remove drugs through electrostatic interactions with their functional groups [21-24], modifying the surface properties of the FeBTC and increasing its interaction energy with diclofenac, naproxen, and ibuprofen. Before and after the material characterization was carried out to identify the drugs' possible adsorption sites in the MOF, the adsorption isotherms and kinetics of the three drugs were studied. In addition, the thermodynamic parameters were calculated for the adsorption of the compounds on the adsorbent.

\section{Materials and Methods}

\subsection{Reagents}

Sodium acetate anhydrous $\left(\mathrm{CH}_{3} \mathrm{COONa}\right.$, purity $\left.\geq 99 \%\right)$, ethylene glycol anhydrous $\left(\mathrm{HOCH}_{2} \mathrm{CH}_{2} \mathrm{OH}\right.$, purity $\geq 99 \%$ ), anhydrous iron nitrate (III) $\left(\mathrm{Fe}\left(\mathrm{NO}_{3}\right)_{3} \cdot 9 \mathrm{H}_{2} \mathrm{O}\right)$, trimesic acid $\left(\mathrm{C}_{6} \mathrm{H}_{3}\left(\mathrm{CO}_{2} \mathrm{H}\right)_{3}\right.$, purity $\left.\geq 95 \%\right), \mathrm{N}, \mathrm{N}$-dimethylformamide anhydrous $\left(\mathrm{HCON}\left(\mathrm{CH}_{3}\right)_{2}\right.$, purity $=99.8 \%$ ), diclofenac sodium salt $\left(\mathrm{C}_{14} \mathrm{H}_{10} \mathrm{C}_{12} \mathrm{NNaO}_{2}\right.$, purity $\left.\geq 98 \%\right)$, naproxen sodium $\left(\mathrm{C}_{14} \mathrm{H}_{13} \mathrm{NaO}_{3}\right.$, purity $\left.\geq 98 \%\right)$, and ibuprofen $\left(\mathrm{C}_{13} \mathrm{H}_{18} \mathrm{O}_{2}\right.$, purity $\left.\geq 98 \%\right)$ were purchased from Sigma-Aldrich, and iron (III) chloride hexahydrate $\left(\mathrm{FeCl}_{3} \cdot 6 \mathrm{H}_{2} \mathrm{O}\right.$, Reag. Ph Eur) was purchased from Ensure.

\subsection{FeBTC synthesis}

The FeBTC MOF was synthesized using the solvothermal method as reported by Rojas et al. [25]. Iron nitrate hexahydrate $(8.7 \mathrm{mmol})$ and trimesic acid $\left(\mathrm{H}_{3} \mathrm{BTC}, 8.3 \mathrm{mmol}\right)$ were added to $30 \mathrm{~mL}$ of $\mathrm{N}, \mathrm{N}$-dimethylformamide (DMF) and sonicated in an ultrasound bath 
for 5 minutes. Subsequently, $30 \mathrm{~mL}$ of ethanol and $30 \mathrm{~mL}$ of deionized water were added to the mixture, which was sonicated for 35 more minutes to ensure complete dissolution of the components. Finally, the mixture was subjected to heating in a sand bath for 24 hours at $358 \mathrm{~K}[26]$.

\section{$2.3 \mathrm{Fe}_{3} \mathrm{O}_{4}$ (magnetite) synthesis}

Magnetite was obtained according the post-synthesis method of Liu et al. [27] with modifications. Briefly, iron (III) chloride hexahydrate $(5.06 \mathrm{mmol})$ and anhydrous sodium acetate $(23.65 \mathrm{mmol})$ were added to $50 \mathrm{~mL}$ of ethylene glycol $(50 \mathrm{~mL})$. The previous dissolution was added in a steel autoclave with Teflon liner $(100 \mathrm{~mL})$. The autoclave was placed at $473 \mathrm{~K}$ for $10 \mathrm{~h}$. The solid obtained was washed with ethanol and water several times to remove impurities. Finally, the magnetite was dried in an oven at $353 \mathrm{~K}$ for $12 \mathrm{~h}$.

\subsection{Synthesis of the $\mathrm{Fe}_{3} \mathrm{O}_{4}-\mathrm{FeBTC}$ composite}

Synthesis of the Fe3O4-FeBTC composite was based on the one-step hydrothermal/solvothermal method reported by Jiang et al. [28]. An exact amount of magnetite (incorporation at 2 and $8 \%$ was also studied, but in this study only the best result is reported: $5 \% \mathrm{wt}$. was added to $30 \mathrm{~mL}$ of ethanol and ultrasonicated to ensure complete dissolution of the components (solution A). Solution B with trimesic acid precursors $(7.88 \mathrm{mmol})$ and iron nitrate hexahydrate $(8.26 \mathrm{mmol})$ was dissolved in DMF. Subsequently, both solutions were mixed and placed into an ultrasound bath for 5 minutes, then $10 \mathrm{~mL}$ of deionized water was added, and the solutions were sonicated for another 30 minutes. The previous solution was kept under vigorous stirring at $358 \mathrm{~K}$ for $24 \mathrm{~h}$. Finally, the composite was dried in an oven at $353 \mathrm{~K}$ for $12 \mathrm{~h}$.

\subsection{Activation of the materials}

For activation of FeBTC and $\mathrm{Fe}_{3} \mathrm{O}_{4}-\mathrm{FeBTC}$ to free up their pores following synthesis, each component was subjected a 3-step procedure. First, they were washed with methanol and then filtered with filter paper. The exact procedure was repeated twice to ensure better activation results. Additionally, the material was placed in an oven at $353 \mathrm{~K}$ for 24 hours, to obtain reddish crystals (Fe III) [7]. Finally, they were stored in a desiccator.

\subsection{Characterization of the materials}

The materials were characterized by powder X-ray diffraction (PXRD) in an X'Pert diffractometer (Philips) with a CuK $\alpha(\lambda=1.54 \AA)$ radiation source, with a step size of $0.02^{\circ}$ in $2 \theta$ per second in the range of 5 to $50^{\circ}$ in $2 \theta, 45 \mathrm{kV}$, and $40 \mathrm{~mA}$. Fourier transform infrared (FTIR) spectra were determined in a Magna-IR 750 device (Thermo Nicolet) by the $\mathrm{KBr}$ pellet technique, using controlled amounts of $\mathrm{KBr}$ (ratio of $1 \mathrm{mg}$ sample to $100 \mathrm{mg} \mathrm{KBr}$ ) to take address the intensity of comparative bands between samples. Raman spectra were recorded by an inVia microscope (Renishaw), using a green laser $(\lambda=532 \mathrm{~nm})$ as the excitation line, 1\% laser power, and a measurement range from 100 to $2000 \mathrm{~cm}^{-1}$. N2 adsorption-desorption isotherm at $77 \mathrm{~K}$ was performed in a BELSORP-Max instrument (BEL JAPAN Inc.). Before analysis, samples were degassed at $403 \mathrm{~K}$ for $24 \mathrm{~h}$ in nitrogen flow to remove water and physisorbed gases.

\subsection{Evaluation of the materials}

Before analyzing the samples, calibration curves were determined by a Varian 100G UVVis spectrometer (Agilent Technologies) using the Lambert-Beer law (Equation (1) [29]:

$$
\boldsymbol{A}_{\lambda}=\varepsilon_{\lambda} \boldsymbol{d} \boldsymbol{C}
$$


where $\mathrm{C}$ is the concentration $(\mathrm{mg} / \mathrm{L}), \mathrm{A}_{\lambda}$ is the absorbance at a specific wavelength; $\mathrm{d}$ is the thickness of the sample contained in the cell $(\mathrm{cm})$, and $\varepsilon_{\lambda}$ is the absorptivity constant $\left((\mathrm{mg} / \mathrm{L})^{-1} \mathrm{~cm}^{-1}\right)$.

Mother solutions of 50 ppm of diclofenac sodium (DCF, $\mathrm{C}_{14} \mathrm{H}_{10} \mathrm{Cl}_{12} \mathrm{NNaO}_{2}, 98 \%$ ), $15 \mathrm{ppm}$ of naproxen sodium (NS, $\mathrm{C}_{14} \mathrm{H}_{13} \mathrm{NaO}_{3}, 98 \%$ ), and 21 ppm of ibuprofen ( $\mathrm{IB}, \mathrm{C}_{13} \mathrm{H}_{18} \mathrm{O}_{2}, 98 \%$ ) were prepared. Then, 6 solutions of different concentrations were prepared to determine the calibration curves of the 3 compounds.

The adsorbed quantity in the materials was calculated from the mass balance with Equation (2), where $\mathrm{C}_{0}$ and $\mathrm{C}_{\mathrm{t}}(\mathrm{mg} / \mathrm{L})$ are the liquid phase concentrations of the pollutant in $\mathrm{t}=$ 0 and $t=t n$, respectively, and $V(L)$ and $W(g)$ are the volume of the solution and the mass of the adsorbent, respectively.

$$
q t=(C 0-C t) \frac{V}{W}
$$

For the adsorption tests, $3 \mathrm{mg}$ of adsorbent was added to $50 \mathrm{~mL}$ of the initial concentration of drug (50 ppm for DCF, 20 ppm for NS, and 15 ppm for IB) at pH values of 4.5 (DCF), 5.6 (NS), and 3.5 (IB) and a temperature of $303 \mathrm{~K}$. After, aliquots were taken at certain adsorption times $(10,15,30,60,120,240$, and $360 \mathrm{~min})$ and analyzed in the UV-Vis spectrometer. The contact time of the material with the contaminant was 6 hours. The final concentration of aliquots was determined using the maximum absorption band at a wavelength of $276 \mathrm{~nm}$ for DCF, $230 \mathrm{~nm}$ for NS, and $221 \mathrm{~nm}$ for IB. To construct the adsorption isotherms, 6 concentrations of each adsorbate were prepared $(5,10,20,30,40$, and $50 \mathrm{ppm}$ for DCF; 2, 3, 6, 9, 12, and 15 ppm for NS; and 2, 4, 8, 12, 16, and 20 ppm for IB). These concentrations were selected because they are the maximum solubility of each drug, and when working with these quantities we will obtain the maximum adsorption capacity concerning this variable.

The multicomponent aqueous mixture was prepared with 50, 15, and 20 ppm of DCF, NS, and $\mathrm{IB}$, respectively, at $\mathrm{pH}$ 5.6. After adsorption of drugs in the adsorbents, the compounds were recovered using an aqueous solution at $\mathrm{pH} 7$ at $308 \mathrm{~K}$ in vigorous stirring for 2 hours.

\section{Results}

\subsection{Material Characterization}

The magnetite nanoparticles had a crystal size of $19.5 \mathrm{~nm}$, measured by the Scherrer equation, and an average particle size of $90 \mathrm{~nm}$, measured by scanning electron microscopy (see the characterization of the magnetite in the supporting information section).

The structures of pristine FeBTC and composite material were obtained by XRD (Figure 2 a). An X-ray diffraction pattern characteristic of pristine FeBTC was observed, one that is consistent with what was reported in the literature [30]. The noise in the diffractograms was attributed to the weak signal obtained from the diffraction of the peaks, caused by the fact that it is a semi-crystalline material with microcrystallinity. Those aberrations were observed not only in this work, but also different reports on this material [6]. In the diffraction pattern of the $\mathrm{Fe}_{3} \mathrm{O}_{4}-\mathrm{FeBTC}$ composite, peaks of pristine FeBTC were observed, with two main peaks at $2 \theta=36$ and $44^{\circ}$, which were assigned to the magnetite nanoparticles [31-33] according to the database (JCPDS 19-0629). Incorporating $\mathrm{Fe}_{3} \mathrm{O}_{4}$ nanoparticles in the FeBTC did not result in any considerable modification of the MOF's structure. 

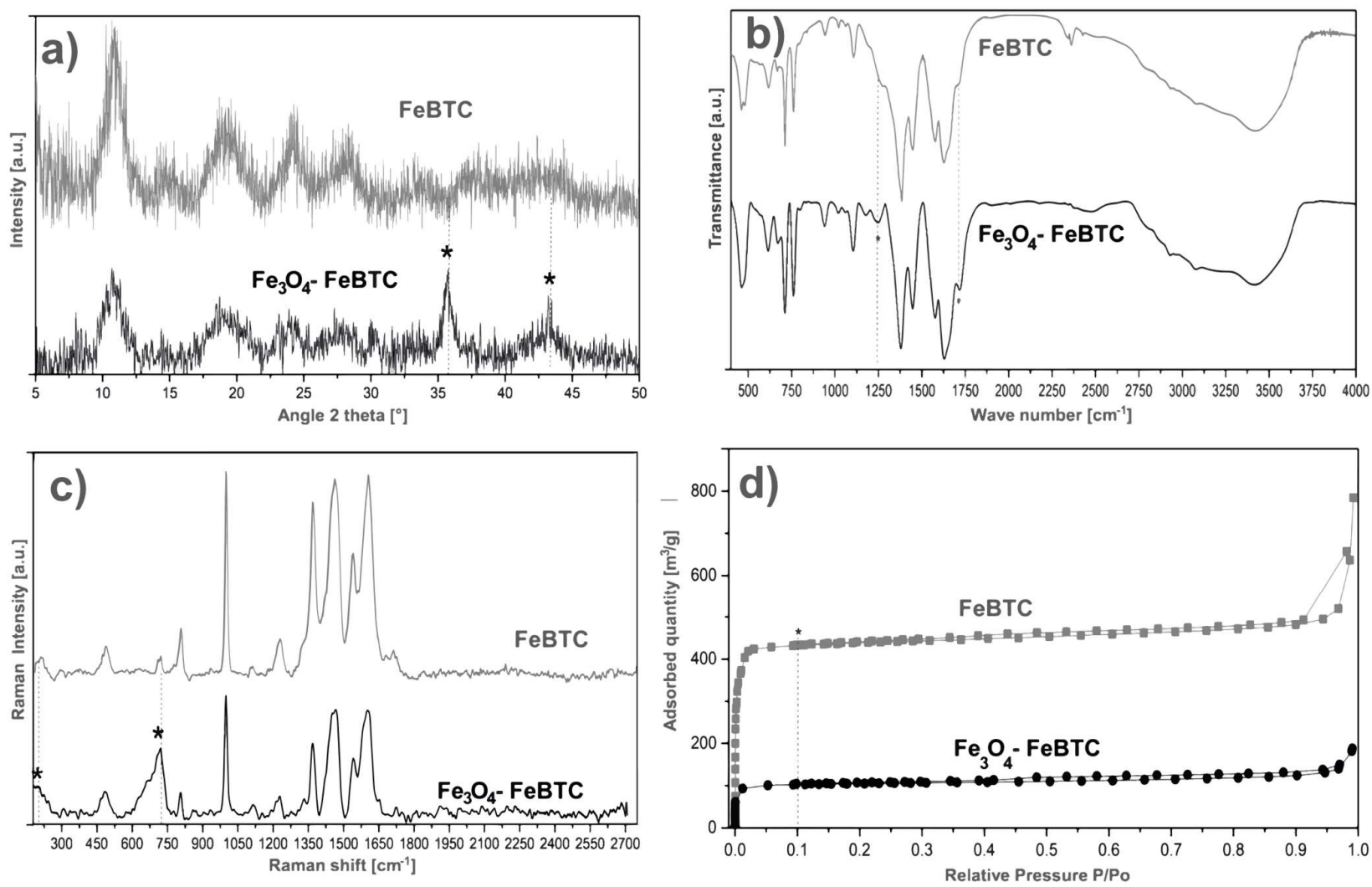

Figure 2. (a) XRD patterns, (b) FTIR spectra, (c) Raman spectra, and (c) $\mathrm{N}_{2}$ adsorption-desorption of FeBTC and $\mathrm{Fe}_{3} \mathrm{O}_{4}-\mathrm{FeBTC}_{\text {at }} 77$ K.

FTIR spectra of pristine FeBTC and composite material are shown in Figure 2b. In general, the bands observed corresponding to the organic ligand (trimesic acid) of the MOF FeBTC spectrum show characteristic bands of the MOFs based on bencentricarboxylate. Several main bands are shown in the $1508-1623 \mathrm{~cm}^{-1}$ region, associated with asymmetric stretching vibrations of BTC carboxylate groups. The maximum bands being at 1384 and 1405 $\mathrm{cm}^{-1}$ is typical of symmetrical stretching vibrations of the same group of bands shown at around $1000 \mathrm{~cm}^{-1}$, representing the $\mathrm{C}-\mathrm{C}$ vibrational groups, and around $760 \mathrm{~cm}^{-1}$, representing the $\mathrm{C}-\mathrm{H}$ bonds of the aromatic ring [34]. A maximum band at $938 \mathrm{~cm}^{-1}$ was observed, corresponding to the metal interacting with carboxylate groups [35]. Other bands were observed at 430,580, and $635 \mathrm{~cm}^{-1}$ [33], assigned to symmetrical and asymmetrical vibrations of the Fe-O bond of the iron oxo-cluster. The Fe (II) cations can be identified through the maximum band located at $430 \mathrm{~cm}^{-1}$, and the Fe (III) with maximum bands at 580 and $635 \mathrm{~cm}^{-1}$ [36]. These same bands were observed in the spectrum of the $\mathrm{Fe}_{3} \mathrm{O}_{4}$ FeBTC composite. Additionally, a band at $1250 \mathrm{~cm}^{-1}$ was observed. Sudman et al. [37] showed that this band could indicate magnetite presence and refers to $\mathrm{C}-\mathrm{O}$ bonding derived from a possible interaction between carboxyl groups and magnetite. Further evidence of magnetite presence is given by the band at around $1600 \mathrm{~cm}^{-1}$, which presents slight unfolding $-\mathrm{a}$ band that is typical of the spectrum of magnetite [38].

Raman spectroscopy was used to determine the structure and presence of magnetite in the composite material. Figure 2c shows the Raman spectra of FeBTC and composite material. Two critical zones were observed in the Raman spectrum: the first zone between 1800 and $730 \mathrm{~cm}^{-1}$ is associated with vibrations of bencentricarboxylate organic ligand, and the second one at less than $600 \mathrm{~cm}^{-1}$ corresponds to the presence of metal coordination with carboxylate groups. More specifically, in the $1612-1003 \mathrm{~cm}^{-1}$ range, vibrations were observed related to the aromatic part of the MOF upon the presence of $\mathrm{C}=\mathrm{C}$. The peaks at 826 and $742 \mathrm{~cm}^{-1}$ are typical of $\mathrm{C}-\mathrm{H}$ group stretching and bending vibrations, respectively. 
The peaks located at 1461 and $1546 \mathrm{~cm}^{-1}$ are related to the presence of symmetrical and asymmetrical vibrations of the carboxyl groups, respectively [39]. On the other hand, the zone associated with the metallic part has certain variations concerning the positioning of the bands related to O-M coordination; they vary between 118 and $500 \mathrm{~cm}^{-1}$. Finally, the bands around $180 \mathrm{~cm}^{-1}$ relate to the $\mathrm{M}-\mathrm{M}$ interaction of the exposed metallic site or "open metal site" [40]. In the Raman spectrum of the composite material, a broad band at around $670 \mathrm{~cm}^{-1}$ is observable which was assigned to magnetite.

The textural properties of FeBTC and composite material were obtained using N2-physisorption at $77 \mathrm{~K}$, and the surface area was acquired by the BET method. The results (Figure $2 \mathrm{~d}$ ) show a type II isotherm characteristic of mesoporous materials according to the IUPAC classification [41]. This result indicates preferential adsorption in the monolayer up to a certain pressure - in this case, around 0.1 relative pressure (point B); above this pressure, a multilayer is formed with lower affinity. The curve that passes above the adsorption process (in the direction of the relative pressure to $\mathrm{P}_{0}=1$ ) is the desorption curve (in the direction of the relative pressure to $P_{0}=0$ ), which returns by a different path due to capillary condensation in the pores of the material. This phenomenon is called a hysteresis loop, and its shape can give us information about geometry and pore type. These materials also show small amounts of hysteresis type H4, confirming the presence of mesoporous materials according to the IUPAC classification, which correspond to pores shaped like an inkwell - spherical with a narrow neck. Decreases in the BET surface area and pore volume compared to pristine FeBTC were observed for the composite material. The decrease in surface area of $\mathrm{Fe}_{3} \mathrm{O}_{4}$-FeBTC compared to pristine FeBTC could have been due to the obstruction of pores by the magnetite nanoparticles or the generation of surface defects from the inclusion of magnetic material; regardless, the pore size increased and its volume decreased (see Table 1).

Table 1. Surface area parameters of FeBTC and $\mathrm{Fe}_{3} \mathrm{O}_{4}-\mathrm{FeBTC}$ metal organic frameworks (MOFs).

\begin{tabular}{cccc}
\hline Material & $\begin{array}{c}\text { Surface area } \\
\text { BET }\left(\mathbf{m}^{2} / \mathbf{g}\right)\end{array}$ & $\begin{array}{c}\text { Total pore } \\
\text { volume }\left(\mathbf{m}^{3} / \mathbf{g}\right)\end{array}$ & $\begin{array}{c}\text { Pore diameter } \\
\text { BJH (nm) }\end{array}$ \\
\hline FeBTC & 815.84 & 0.92 & 3.26 \\
Fe $_{3} \mathrm{O}_{4}$-FeBTC & 217.04 & 0.86 & 3.71 \\
\hline
\end{tabular}

3.2 Adsorption of pollutants on materials

\subsubsection{Adsorption kinetics}

Generally, the kinetic models that best describe the adsorption process in carbon materials are pseudo-first-order (Equation (3)) or pseudo-second-order (Equation (4)) equations, and sometimes the Elovich equation (Equation (5)) [42]:

$$
\begin{gathered}
q t=q e\left[1-e\left(-k_{1} t\right)\right] \\
q t=\frac{\left(q e^{2} k_{2} t\right)}{\left(q e k_{2} t+1\right)} \\
q t=\frac{1}{\beta} \ln (\alpha \beta)+\frac{1}{\beta} \ln (t)
\end{gathered}
$$

where $\mathrm{t}(\mathrm{min})$ is a specific period of time; $\mathrm{qt}$ and $\mathrm{qe}(\mathrm{mg} / \mathrm{g})$ are the drug amount adsorbed at time $\mathrm{t}$ and at the equilibrium, respectively; $\mathrm{k}_{1}\left(\mathrm{~min}^{-1}\right)$ and $\mathrm{k}_{2}\left(\mathrm{~g} / \mathrm{mg} \mathrm{min}^{-1}\right)$ are the adsorption constants for the pseudo-first order and pseudo-second order; and $\alpha\left(\mathrm{mg} / \mathrm{g} \mathrm{min}^{-1}\right)$ and $\beta(\mathrm{g} / \mathrm{mg})$ are the Elovich constants. 
The kinetic adsorption model of NSAIDs in FeBTC and $\mathrm{Fe}_{3} \mathrm{O}_{4}-\mathrm{FeBTC}$ (Figure 3) fits a pseudo-second-order model, with a suitable correlation coefficient for pollutant adsorption (Table 2). The average time for the equilibrium adsorption was $240 \mathrm{~min}$.

The rate constant $\mathrm{k}_{2}$ shows how fast the adsorption process of each drug in the materials reaches equilibrium; the higher this coefficient, the higher the adsorption speed. In general, ibuprofen is absorbed faster and naproxen takes the longest to reach equilibrium. FeBTC reaches equilibrium slightly earlier than the composite material, which could be attributed to clogging of magnetite pores.
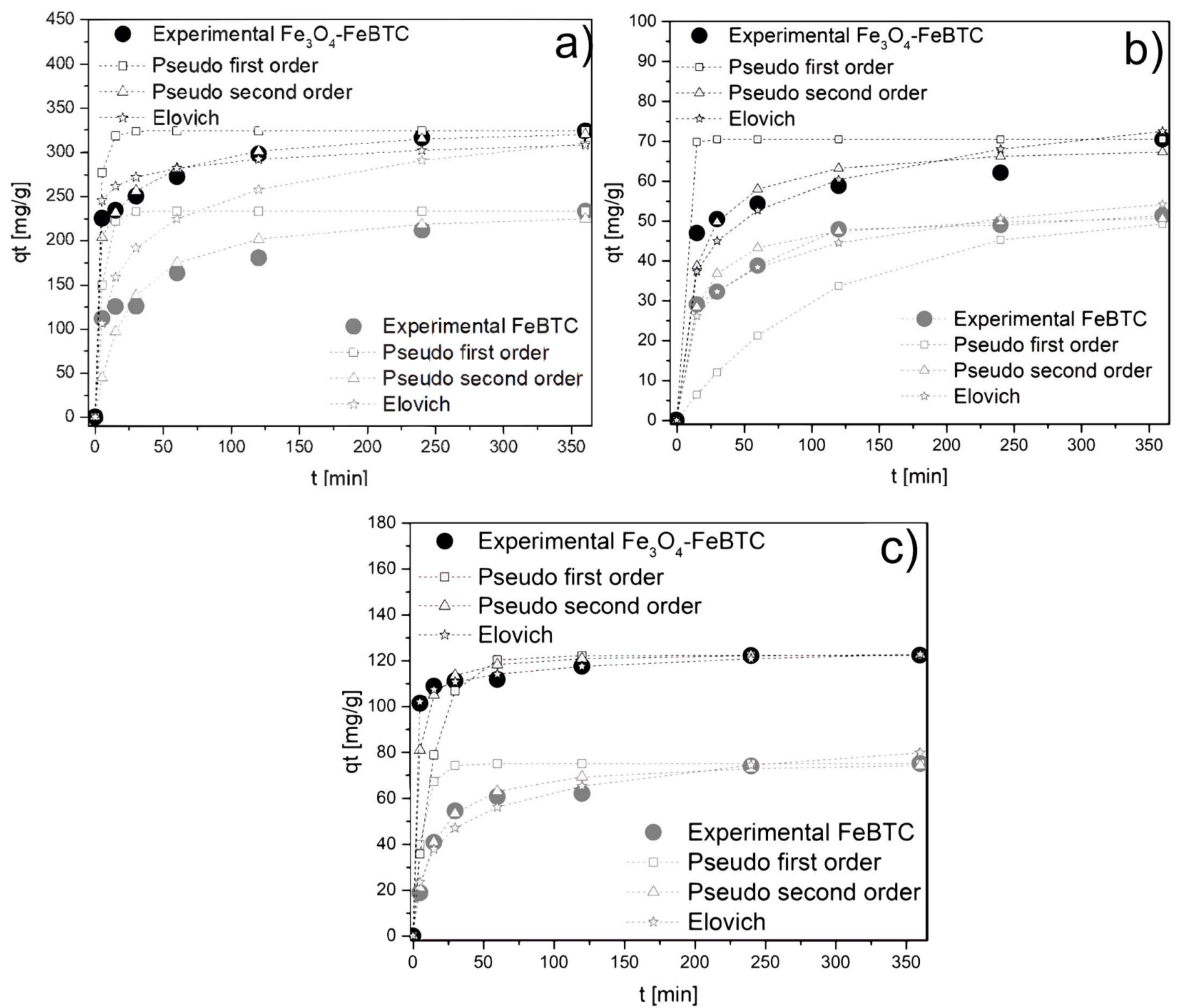

Figure 3. Effects of contact time on adsorption of (a) diclofenac sodium, (b) naproxen sodium, and (c) ibuprofen on FeBTC and $\mathrm{Fe}_{3} \mathrm{O}_{4}-\mathrm{FeBTC}$ by different kinetic methods. Reaction conditions: $3 \mathrm{mg}$ of adsorbent; reaction temperature $303 \mathrm{~K} ; \mathrm{pH} 4.5$ (DCF), 5.6 (NS), and 3.5 (IB); initial concentrations of 50 ppm (DCF), 15 ppm (NS), and 20 ppm (IB).

Table 2. Kinetic parameters obtained from adsorption of contaminants in MOFs FeBTC and $\mathrm{Fe}_{3} \mathrm{O}_{4}-\mathrm{FeBTC}$.

\begin{tabular}{|c|c|c|c|c|c|c|c|}
\hline \multirow[t]{2}{*}{ Model } & \multirow[t]{2}{*}{ Parameter } & \multicolumn{2}{|c|}{ Diclofenac sodium } & \multicolumn{2}{|c|}{ Naproxen sodium } & \multicolumn{2}{|c|}{ Ibuprofen } \\
\hline & & FeBTC & $\begin{array}{l}\mathrm{Fe}_{3} \mathrm{O}_{4}- \\
\text { FeBTC }\end{array}$ & FeBTC & $\begin{array}{l}\mathrm{Fe}_{3} \mathrm{O}_{4}- \\
\text { FeBTC }\end{array}$ & FeBTC & $\begin{array}{l}\mathrm{Fe}_{3} \mathrm{O}_{4-} \\
\text { FeBTC }\end{array}$ \\
\hline & qt $(\mathrm{mg} / \mathrm{g})$ & 139 & 233.1 & 51.2 & 70.4 & 75.1 & 102.6 \\
\hline
\end{tabular}




\begin{tabular}{|c|c|c|c|c|c|c|c|}
\hline $\begin{array}{c}\text { Pseudo } \\
\text { first order }\end{array}$ & $\begin{array}{c}\mathrm{K}_{1}\left(\min ^{-1}\right) \\
\mathrm{R}^{2}\end{array}$ & $\begin{array}{c}0.22 \\
0.994\end{array}$ & $\begin{array}{c}0.2 \\
0.981\end{array}$ & $\begin{array}{c}0.01 \\
0.920\end{array}$ & $\begin{array}{c}0.31 \\
0.962\end{array}$ & $\begin{array}{c}0.15 \\
0.950\end{array}$ & $\begin{array}{c}0.23 \\
0.920\end{array}$ \\
\hline \multirow{3}{*}{$\begin{array}{c}\text { Pseudo } \\
\text { second or- } \\
\text { der }\end{array}$} & qt (mg/g) & 149.3 & 238.1 & 52.4 & 69.4 & 76.9 & 114.9 \\
\hline & $\mathrm{K}_{2}(\mathrm{~g} / \mathrm{mg} \min )$ & $9.31 \times 10^{-6}$ & $\begin{array}{c}1.62 \times 10^{-} \\
6\end{array}$ & $8.85 \times 10^{-7}$ & $3.56 \times 10^{-7}$ & $2.91 \times 10^{-5}$ & $\begin{array}{c}2.39 \times \\
10^{-5}\end{array}$ \\
\hline & $\mathrm{R}^{2}$ & 0.995 & 0.991 & 0.997 & 0.990 & 0.990 & 0.940 \\
\hline \multirow{3}{*}{ Elovich } & $\beta(\mathrm{mg} / \mathrm{g})$ & 85.53 & 87.96 & 11.35 & 21.43 & 15.54 & 14.47 \\
\hline & $\alpha(\mathrm{g} / \mathrm{mg} \min )$ & 0.068 & 0.021 & 0.113 & 0.090 & 0.076 & 0.052 \\
\hline & $\mathrm{R}^{2}$ & 0.971 & 0.924 & 0.981 & 0.930 & 0.970 & 0.930 \\
\hline
\end{tabular}

\subsubsection{Adsorption isotherms}

The adsorption models were used to calculate the theoretical adsorption from the experimental data, since the parameters obtained had so much importance in evaluating the adsorbent's effectiveness. The most representative models that usually well describe the process of NSAID adsorption on MOFs are the Langmuir (Equation (6)), Freundlich (Equation (7)), Temkin (Equation (8)), and Dubinin-Radushkevich (Equation (9)) models:

$$
\begin{array}{r}
q e=\frac{q m k L C e}{1+k L C e} \\
q e=k_{F} C e^{(1 / n)} \\
q e=A \ln \left(C e k_{T}\right) \\
q e=q m \exp \left[k_{D R}[\ln (1+1 / C e)]^{2}\right]
\end{array}
$$

where $\mathrm{Ce}(\mathrm{mg} / \mathrm{L})$ represents the equilibrium aqueous solution concentration; qe and $\mathrm{qm}(\mathrm{mg} / \mathrm{g})$ are the equilibrium and maximum adsorptive capacity, respectively; $\mathrm{kL}_{\mathrm{L}}(\mathrm{L} / \mathrm{mg}), \mathrm{kF}_{\mathrm{F}} \mathrm{k}_{\mathrm{T}}$, and $\mathrm{kDR}_{\mathrm{Dr}}$ are the Langmuir, Freundlich, Temkin, and Dubinin-Radushkevich adsorption constants, respectively, which also have thermodynamic information about the affinity adsorbent-adsorbate; and $\mathrm{n}$ and A are dimensionless constants.

Figure 4 shows the adsorption isotherms for FeBTC and $\mathrm{Fe}_{3} \mathrm{O}_{4}-\mathrm{FeBTC}$ for DCF, NS, and IB, adjusted for the different adsorption models. Table 3 shows the parameters obtained from the isotherms of pollutants in FeBTC and $\mathrm{Fe}_{3} \mathrm{O}_{4}$-FeBTC MOFs. DCF adsorption in the materials adjusted better to the Langmuir model, indicating the presence of an energetically homogeneous surface during the adsorption process. On the other hand, there was minimal interaction between DCF molecules, suggesting that the adsorption process just forms a monolayer.

The naproxen adsorption process of the MOF is well depicted by the Freundlich model using FeBTC material and the Temkin model for $\mathrm{Fe}_{3} \mathrm{O}_{4}-\mathrm{FeBTC}$ composite. In this case, the adsorption energy decreased while the naproxen molecule's adsorption increased; therefore, the highest energy sites are on the material modified surface, without adsorbateadsorbate or weak interactions. 
Finally, ibuprofen adsorption in the FeBTC is better described by the Langmuir model. However, when the magnetite is incorporated, the experimental data are better described with the Freundlich model, probably due to an energetic modification after adding the magnetic material.
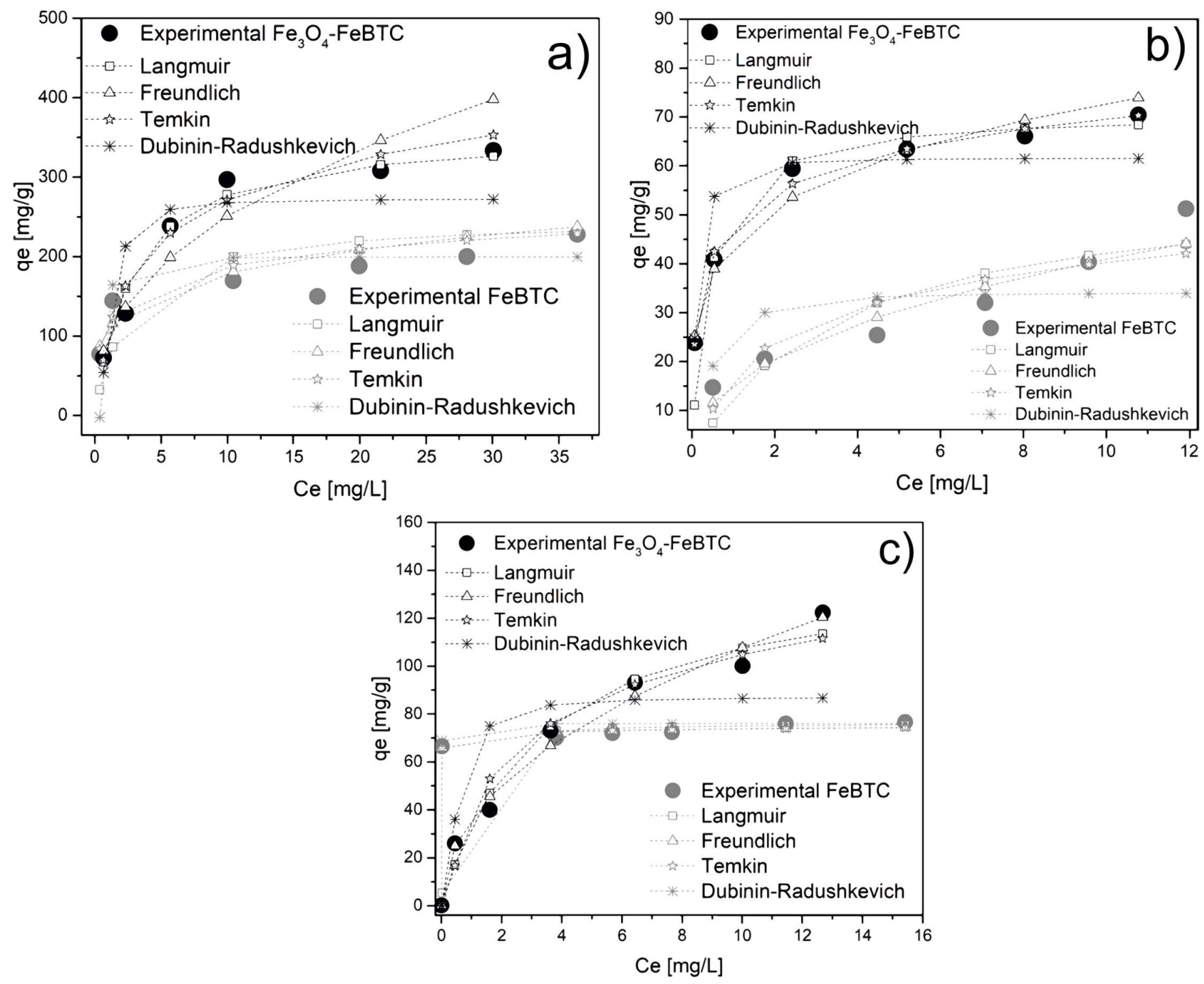

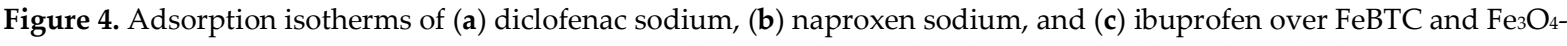
FeBTC, comparing Langmuir, Freundlich, Temkin, and Dubinin-Radushkevich methods.

The FeBTC maximum adsorption capacity for NSAID pollutants was increased by the influence of magnetite, as shown in Table 3. The improved adsorption could be attributed to magnetite modifying the surface of the material through the addition of superficial defects (substitutional)[43,44], providing energy to the electrostatic energy [9] that magnetite already possesses by itself and favors the interaction of bonds [45]. Although the composite material had a significantly smaller surface area, H-bonding possibly played a vital role in NSAID adsorption.

Table 3. Langmuir, Freundlich, Temkin, and Dubinin-Radushkevich parameters obtained from isotherms of pollutants in FeBTC and $\mathrm{Fe}_{3} \mathrm{O}_{4}$-FeBTC MOFs. 


\begin{tabular}{|c|c|c|c|c|c|c|c|}
\hline \multirow[t]{2}{*}{ Model } & \multirow[t]{2}{*}{ Parameter } & \multicolumn{2}{|c|}{ Diclofenac sodium } & \multicolumn{2}{|c|}{ Naproxen sodium } & \multicolumn{2}{|c|}{ Ibuprofen } \\
\hline & & FeBTC & $\begin{array}{l}\mathrm{Fe}_{3} \mathrm{O}_{4-} \\
\mathrm{FeBTC}\end{array}$ & FeBTC & $\begin{array}{l}\mathrm{Fe}_{3} \mathrm{O}_{4-} \\
\text { FeBTC }\end{array}$ & FeBTC & $\begin{array}{l}\mathrm{Fe}_{3} \mathrm{O}_{4-}- \\
\mathrm{FeBTC}\end{array}$ \\
\hline \multirow{3}{*}{ Langmuir } & $\mathrm{q}_{\mathrm{m}}(\mathrm{mg} / \mathrm{g})$ & 2.47 .5 & 347.1 & 56.8 & 70.9 & 76.3 & 142.9 \\
\hline & $\mathrm{K}_{\mathrm{L}}(\mathrm{L} / \mathrm{min})$ & 0.40 & 0.35 & 0.29 & 0.25 & 0.54 & 0.30 \\
\hline & $\mathrm{R}^{2}$ & 0.987 & 0.989 & 0.854 & 0.98 & 0.990 & 0.961 \\
\hline \multirow{3}{*}{ Freundlich } & $\mathrm{n}$ & 4.6 & 2.4 & 4.6 & 2.7 & 5.8 & 2.1 \\
\hline & $\mathrm{K}_{\mathrm{F}}((\mathrm{g} / \mathrm{mg})(\mathrm{L} / \mathrm{mg}))$ & 108.3 & 96.1 & 44.2 & 17.1 & 70.8 & 36.4 \\
\hline & $\mathrm{R}^{2}$ & 0.904 & 0.911 & 0.956 & 0.970 & 0.750 & 0.979 \\
\hline \multirow{3}{*}{ Temkin } & $\mathrm{K}_{\mathrm{F}}(\mathrm{J} / \mathrm{mol})$ & 79.4 & 36.9 & 2.68 .9 & 248.6 & 207.1 & 88.9 \\
\hline & $\mathrm{A}(\mathrm{L} / \mathrm{mg})$ & 34.0 & 3.9 & 16.7 & 5.6 & 21.5 & 4.0 \\
\hline & $\mathrm{R}^{2}$ & 0.910 & 0.903 & 0.804 & 0.990 & 0.730 & 0.941 \\
\hline \multirow{3}{*}{$\begin{array}{c}\text { Dubinin- } \\
\text { Radush- } \\
\text { kevich }\end{array}$} & $\mathrm{q}_{\mathrm{s}}(\mathrm{mg} / \mathrm{g})$ & 199.5 & 272.3 & 34.0 & 61.6 & 75.9 & 86.9 \\
\hline & $\mathrm{KDR}\left((\mathrm{mol} / \mathrm{J})^{2}\right)$ & $\begin{array}{c}1 \times 10^{-} \\
7\end{array}$ & $3 \times 10^{-7}$ & $1 \times 10^{-7}$ & $2 \times 10^{-7}$ & $3 \times 10^{-10}$ & $1 \times 10^{-7}$ \\
\hline & $\mathrm{R}^{2}$ & 0.876 & 0.791 & 0.617 & 0.890 & 0.821 & 0.731 \\
\hline
\end{tabular}

\subsubsection{Adsorption thermodynamic parameters}

Adsorption enthalpy $\left(\Delta \mathrm{H}^{\circ}\right)$, and free energy $\left(\Delta \mathrm{G}^{\circ}\right)$ and entropy $\left(\Delta \mathrm{S}^{\circ}\right)$, can be calculated according to Equations [10] and [11] equations [43]:

$$
\begin{gathered}
\ln \frac{q e}{\boldsymbol{C e}}=\frac{-\Delta H^{\circ}{ }_{a d s}}{\boldsymbol{R}} T^{-1}+\frac{\Delta \boldsymbol{S}^{\circ}}{\boldsymbol{R}} \\
\Delta G^{\circ}=\Delta H^{\circ}-T \Delta S^{\circ}
\end{gathered}
$$

where $\mathrm{R}$ is the constant of gases $(8.314 \mathrm{~J} / \mathrm{mol} \mathrm{K})$ and $\mathrm{T}$ is the temperature in Kelvin.

Adsorption tests were carried out at different temperatures (293, 298, 303, 213, and $318 \mathrm{~K})$ at a maximum concentration of adsorbate ( $50 \mathrm{ppm}$ for DFC, $15 \mathrm{ppm}$ for NS, and $20 \mathrm{ppm}$ for IB) in $50 \mathrm{~mL}$ solutions and with $3 \mathrm{mg}$ of MOF adsorbent material. The obtained values of the thermodynamic properties for $\mathrm{FeBTC}$ and $\mathrm{Fe}_{3} \mathrm{O}_{4}-\mathrm{FeBTC}$ are shown in Table 4.

Table 4. Thermodynamic data of adsorption for drugs on FeBTC and $\mathrm{Fe}_{3} \mathrm{O}_{4}-\mathrm{FeBTC}$.

\begin{tabular}{|cccccc|}
\hline \multirow{2}{*}{ Drug } & Material & $\begin{array}{c}\Delta \mathbf{H}^{\circ} \\
\mathbf{( k J} / \mathbf{m o l})\end{array}$ & $\begin{array}{c}\Delta \mathbf{S}^{\circ} \\
\mathbf{( k J} / \mathbf{m o l ~ K})\end{array}$ & $\begin{array}{c}\Delta \mathbf{G}^{\circ} \\
\mathbf{( k J} / \mathbf{m o l})\end{array}$ & $\mathbf{R}^{2}$ \\
\hline \multirow{2}{*}{ DCF } & FeBTC & -10.26 & -0.007 & -6.7 & 0.995 \\
& $\mathrm{Fe}_{3} \mathrm{O}_{4}-\mathrm{FeBTC}$ & -34.09 & -0.083 & -7.4 & 0.990 \\
\hline \multirow{2}{*}{ NS } & FeBTC & -28.87 & -0.079 & -4.2 & 0.988 \\
& $\mathrm{Fe}_{3} \mathrm{O}_{4}-\mathrm{FeBTC}$ & -45.89 & -0.138 & -2.8 & 0.991 \\
\hline \multirow{2}{*}{ IB } & FeBTC & -75.04 & -0.226 & -8.2 & 0.996 \\
& $\mathrm{Fe}_{3} \mathrm{O}_{4}-\mathrm{FeBTC}$ & -80.03 & -0.240 & -9.0 & 0.994 \\
\hline
\end{tabular}

In all pollutant adsorption processes, the free energy change $\left(\Delta G^{\circ}\right)$ is negative, which indicates that it is a spontaneous process. For the enthalpy change $\left(\Delta \mathrm{H}^{\circ}\right)$, all values are negative, suggesting an exothermic process in most tests. At the same time, it is possible to detect lower energy values, as we can observe how lower energy values are obtained $\left(\Delta \mathrm{H}^{\circ}\right.$ 
$>-40 \mathrm{~kJ} / \mathrm{mol}$ ), which indicates a physisorption process. In the case of ibuprofen adsorption, higher energy values are obtained $\left(\Delta \mathrm{H}^{\circ}>-40 \mathrm{~kJ} / \mathrm{mol}\right)$, which refers to a process of chemisorption [46]. The negative value of entropy indicates a decrease of the randomness in the solid-liquid interface during the adsorption process and a lower degree of freedom of the adsorbed species [47], represented by $\Delta S^{\circ}$ values near zero.

\subsubsection{Multi-component mixture adsorption}

Table 4 shows the adsorption capacity of the multicomponent mixture of DCF, NS, and IB by $\mathrm{FeBTC}$ and $\mathrm{Fe}_{3} \mathrm{O}_{4}-\mathrm{FeBTC}$ materials at $303 \mathrm{~K}$ and $\mathrm{pH}$ 5.6, and pollutant drug recovery capacity after desorption in water at $303 \mathrm{~K}$ and $\mathrm{pH} 7$.

In the multicomponent mixture adsorption study, the most adsorptive component was ibuprofen, and next came diclofenac, according to their maximum capacities in a simple system (122.9 and $357.1 \mathrm{mg} \mathrm{g}^{-1}$, respectively, for $\mathrm{Fe}_{3} \mathrm{O}_{4}-\mathrm{FeBTC}$ ); naproxen adsorption in the simple system reached $70 \mathrm{mg} \mathrm{g}^{-1}$ for $\mathrm{Fe}_{3} \mathrm{O}_{4}$-FeBTC. The single MOF and the composite had a better affinity for ibuprofen, since the adsorption heat values are the highest among the NSAIDs, to the point of exceeding the physisorption limit, indicating the presence of a chemisorption adsorption process, with $\Delta \mathrm{H}^{\circ}$ values up to $50 \mathrm{~kJ} / \mathrm{mol}$. This can be observed in the recovery of ibuprofen, which was below $10 \%$ for FeBTC. Adsorption close to $100 \%$ could not be expected for each drug compared to the simple system, because there is competitive adsorption at the same type of site.

On the other hand, naproxen recovery was almost $87 \%$ in $\mathrm{Fe}_{3} \mathrm{O}_{4}-\mathrm{FeBTC}$. DCF had the lowest adsorption energy compared to the other NSAIDs, and therefore was expected to be the one with the highest amount recovered, but only $85 \%$ was recovered for $\mathrm{Fe}_{3} \mathrm{O}_{4}-\mathrm{FeBTC}$. This result could be explained by considering sites with higher interaction energy and greater affinity with adsorbate, and the data are shown in Table 5.

Table 5. Adsorption capacity of multicomponent mixture and recovery of Nonsteroidal Anti-inflammatory Drugs.

\begin{tabular}{|c|c|c|c|c|c|c|}
\hline \multirow[b]{2}{*}{ Material } & \multicolumn{3}{|c|}{ Multicomponent drug adsorption $(\mathrm{mg} / \mathrm{g})$} & \multicolumn{3}{|c|}{ Multicomponent drug recovery (mg/g) } \\
\hline & DCF & NS & IB & DCF & NS & IB \\
\hline FeBTC & 162.5 & 18.7 & 102.7 & $146.3(90 \%)$ & $16.4(87 \%)$ & $13.3(13 \%)$ \\
\hline $\mathrm{Fe}_{3} \mathrm{O}_{4}-\mathrm{FeBTC}$ & 204.1 & 18.2 & 117.9 & $124.7(61 \%)$ & $15.6(85 \%)$ & $12.6(11 \%)$ \\
\hline
\end{tabular}

3.2.5 Effects of adsorbent mass, temperature, and $\mathrm{pH}$ on the adsorption process

To understand the MOF-drug adsorption process, it was decided to analyze how the variables of the process affect it; for this, the concentration of adsorbent, temperature, and $\mathrm{pH}$ were studied.

The adsorption capacity differences ( $\left.\mathrm{mg}_{\text {adsorbent }} / \mathrm{g}_{\text {adsorbate}}\right)$ concerning the amount of adsorbent shows that the lower the adsorbent/adsorbate ratio, the higher the adsorption capacity. The explanation for the increase in adsorption capacity is that the adsorbate increases the chance of contact with the adsorbent surface. This behavior occurred in both materials with all NSAIDs. 
After studying the influence of temperature on the adsorption process, a slight increase in the adsorption capacity of drugs was seen when the temperature decreased. This shows the exothermic and spontaneous nature of the process.

$\mathrm{pH}$ is shown to be the variable that most influences the adsorption process; for high $\mathrm{pH}$ values, adsorption decreases. Since the adsorption capacity decreases significantly when the $\mathrm{pH}$ rises for all NSAIDs, according to the values found in this research work, the isoelectric point at $\mathrm{pH} 4.6$ and 4.1 for FeBTC and Fe3O4-FeBTC, respectively, would guarantee a positive surface charge density in the MOF and composite materials, obtaining a good interaction with the NSAIDs at values above their pka (4 and 4.2 for DCF and NS, respectively). Below these values, they lose solubility; IB is soluble up to $\mathrm{pH} 3$ [9]. This shows that $\mathrm{pH}$ is the most important variable in the adsorption process and surface electrostatic interactions.

\subsubsection{Characterization of materials after adsorption}

After adsorption, the materials were characterized by XRD and Raman spectroscopy, as shown in Figure 5. The X-ray diffraction pattern of pristine FeBTC after adsorption showed a decrease in peak intensity. Additional peaks were observed associated with $\alpha$ FeOOH [47], corresponding to the JCPDS data (JCPDS number 29-0713) (Figure 5a).

Raman spectra (Figure 5b) show that the MOF and composite structures remained completely stable after pollutants were added in an aqueous solution in the range of $\mathrm{pH}$ 3.55. The most common difference is shown in the two materials after adsorbing the NSAIDs; the band's relative intensity associated with the metal cluster intensified, and the bands at around 125 and $180 \mathrm{~cm}^{-1}$ separated and looked more pronounced. In addition, a shift of the bands at 1461 and $1546 \mathrm{~cm}^{-1}$ was observed for both materials, attributed to the bonds of the carboxylate group attached to the metal clusters and the open metal sites, which is evidence of an interaction of drugs at these sites. Another band observed with greater relative intensity is the band at $1003 \mathrm{~cm}^{-1}$ associated with the $\mathrm{C}=\mathrm{C}$ bonds of the aromatic part of the MOF. This confirms that the most critical interaction sites are the $\mathrm{C}=\mathrm{C}$ bonds reported by different authors, and $\pi$ interactions between the aromatic groups of the MOF and those that make up the NSAIDs, in addition to a strong interaction in the metal cluster translated as electrostatic interaction, supported by evidence shown by other researchers $[9,10]$.

The only MOF that presented a significant change at 1250 and $1700 \mathrm{~cm}^{-1}$ was $\mathrm{Fe}_{3} \mathrm{O}_{4}-\mathrm{FeBTC}_{\text {, }}$ which may be because the NSAIDs began to be adsorbed in another area to the surface energy modification produced by the incorporation of magnetite.
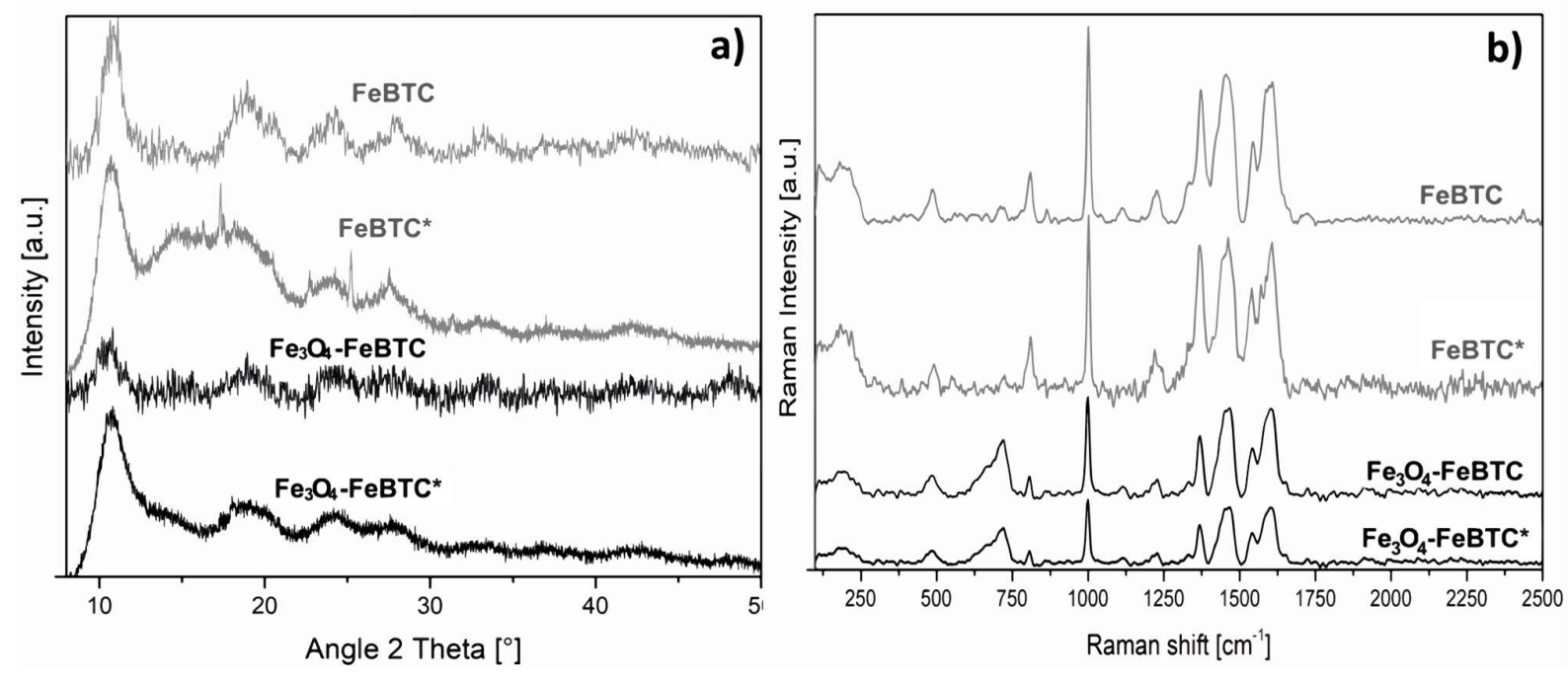
Figure 5. (a) X-ray diffractogram and (b) Raman spectra of materials in their pristine state and $\left(^{*}\right)$ after adsorption process with pollutants.

On the other hand, in the FeBTC diffraction pattern, a structural disturbance was observed after the adsorption process, unlike $\mathrm{Fe}_{3} \mathrm{O}_{4}$-BTC, which maintained the same diffractogram. Although the FeBTC continued to preserve its structure, a typical diffraction pattern of partial collapse was observed, which did not occur in the composite material since the magnetite provides stability for the MOF. The decrease in the characteristic peaks of magnetite nanoparticles in FeBTC could be due to re-dispersion or size reduction. The X-ray technique can no longer detect since the presence of the material is confirmed by Raman spectroscopy.

The results of the Raman spectroscopy analysis of NSAIDs in our previous work [10] helped us to build the model or interaction shown in Figure 6.

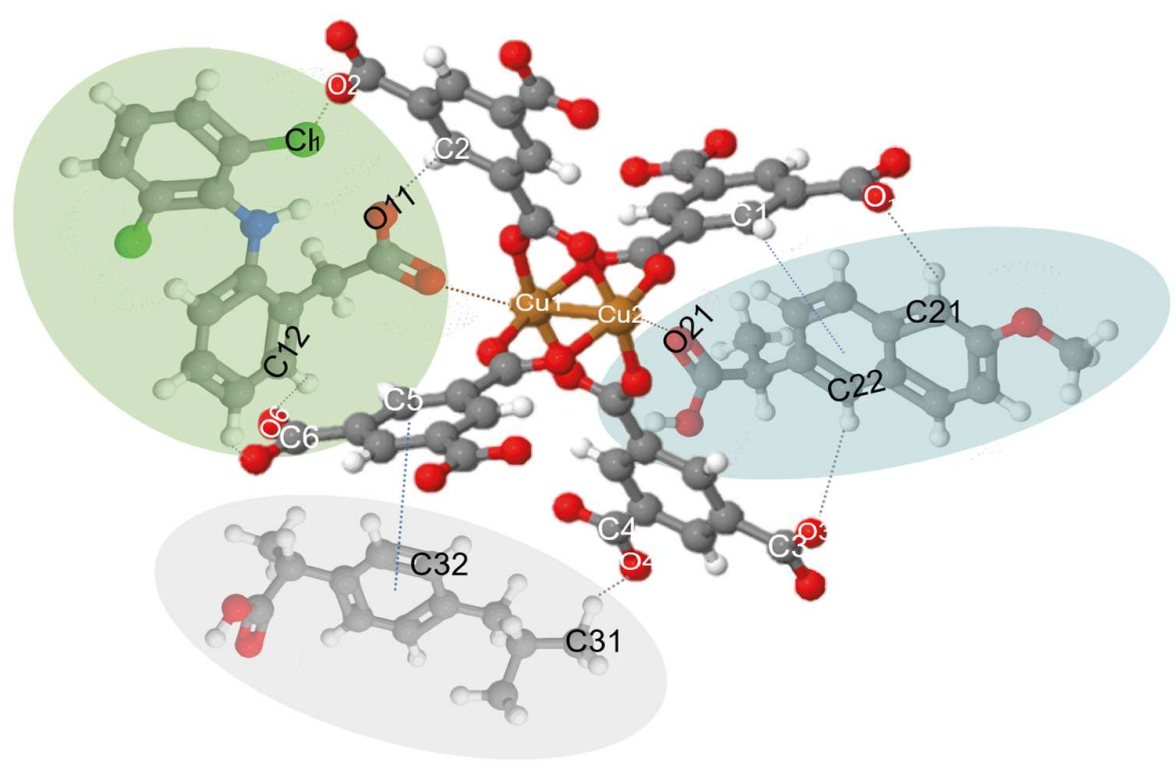

Figure 6. Possible interactions of drug molecules (DCF, NS, and IB) with MOF structure. (C: gray; H: white; O: blue; Cu: orange; $\mathrm{Cl}$ : yellow; $\mathrm{N}$ : green; DCF: green oval; NS: blue oval; IB: gray oval.)

\subsubsection{Reutilization and economy}

The reuse process is crucial when looking for materials to remedy environmental problems; for this purpose, it is necessary to study and guarantee the material's efficiency in different adsorption cycles. These materials were shown to be easily regenerated using only water and modifying the $\mathrm{pH}$ at room temperature, in addition to recovering the drug from the adsorbent material. Figure 7 shows three reuse cycles for FeBTC and $\mathrm{Fe}_{3} \mathrm{O}_{4}$ FeBTC in the adsorption process of the three drugs. In the gray scale (for diclofenac adsorption), almost constant adsorption is observed for both materials; in the blue scale (naproxen adsorption), almost constant adsorption is also observed; in the green scale (ibuprofen adsorption), it is observed that after the first cycle, the adsorption decreases. The only drug that has decreased adsorption efficiency (Figure 7) is ibuprofen, since it is chemically adsorbed at some sites. This is because the enthalpy of adsorption of ibuprofen is such that it chemisorbs and deactivates some sites, leaving them unavailable for subsequent adsorption.

According to the values obtained, 1 gram has the capacity to treat more than 16 liters of contaminated water at maximum amounts with NSAIDs. Regarding the values obtained 
from the adsorption kinetics, 200 liters of water could be treated in one day. The reusability of this material makes it a good candidate for the sequestration of not only drugs but also heavy metals, inorganic compounds, colorants, etc.

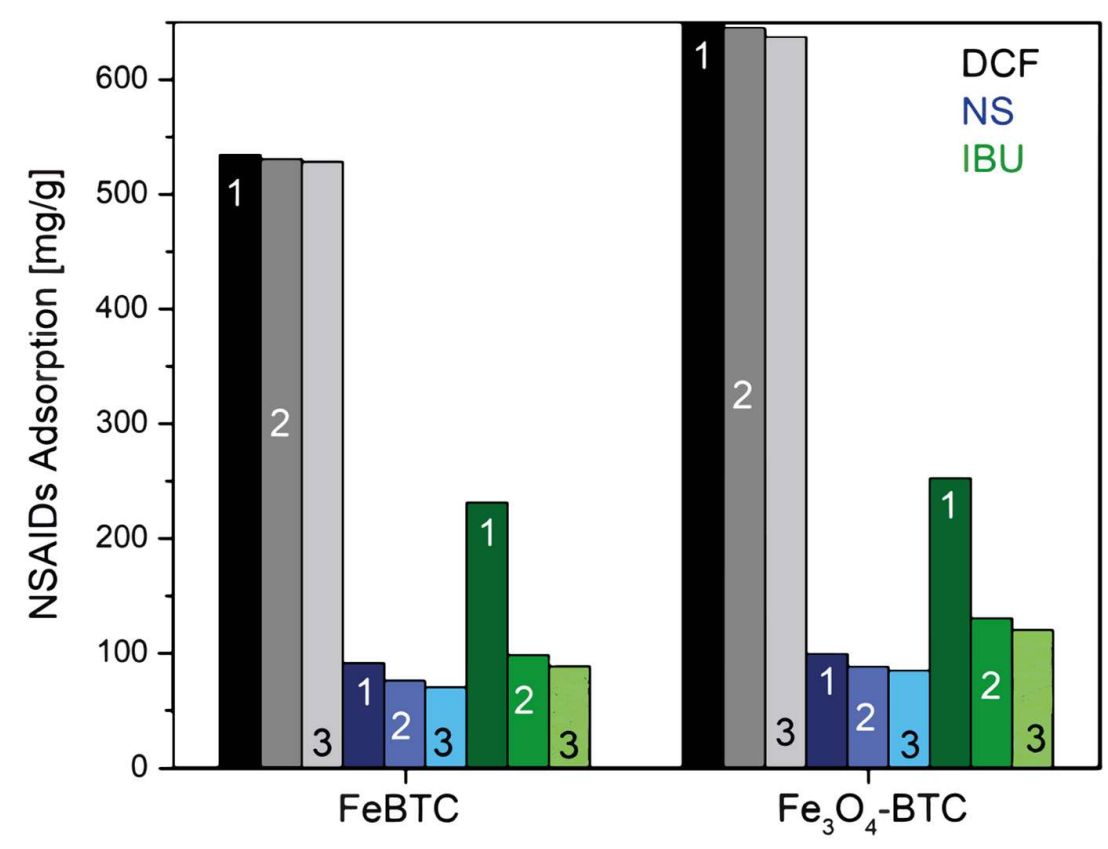

Figure 7. Adsorption cycles for three drugs on pristine FeBTC MOF and magnetite $\mathrm{Fe}_{3} \mathrm{O}_{4}-\mathrm{FeBTC}_{\mathrm{C}}$ composite.

\section{Conclusions}

A novel and stable composite material based on an FeBTC MOF was prepared using a solvothermal method incorporating magnetite in situ. It was used for removing drug pollutants (naproxen sodium (NS), diclofenac sodium (DCF), and ibuprofen (IB)) in an aqueous medium. X-ray and Raman spectroscopy analysis confirmed the presence of magnetite in the composite material.

A pseudo-second-order kinetic model can describe the adsorption process. The thermodynamic study revealed that adsorption of the three drugs was a feasible, spontaneous, and exothermic process. XRD and Raman analysis confirmed the stability of $\mathrm{Fe}_{3} \mathrm{O}_{4}$-FeBTC after the pollutant adsorption process, and the main sites and principal effects in the structure through the modification of bands in the spectrum refer to one interacting with another, thus evidencing the exposed open-metal sites as one of the main areas of interaction of adsorbent with adsorbate.

The composite material presented an increase in surface heterogeneity compared to the MOF without magnetite; this was observed through the Freundlich empirical adsorption model for most drugs, indicating a non-ideal adsorption process on an energetically heterogeneous adsorption surface with little interaction between adsorbate molecules. This heterogeneity could be due to the inclusion of new higher-energy structural defects that decrease the material's specific area, decreased pore volume, and pore obstruction by magnetite. The comparison of Raman spectroscopy before and after the adsorption process showed a small decay of the $\mathrm{C}-\mathrm{C}, \mathrm{C}-\mathrm{O}$, and $\mathrm{O}-\mathrm{Fe}$ vibration bands, which indicates that the adsorption sites are carried in the open metal sites and by $\pi-\pi$ staking. 
Even though magnetite incorporation did not modify the structure of the material for three regeneration cycles, it changed the surface, increasing the non-coordinated active sites and the number of available sites. Due to this, the surface energy of the material increased. This is because, after adding the magnetite, the number of active Fe-O sites increased.

The study of adsorption enthalpy showed that the adsorption of all drugs is an exothermic process and therefore spontaneous; diclofenac and naproxen had physisorption energy, while ibuprofen was chemisorbed. In multicomponent adsorption, it was shown that ibuprofen was preferentially adsorbed, followed by diclofenac, consistent with the adsorption energy found.

Although the recovery of contaminants was relatively good for diclofenac and naproxen, chemisorbed ibuprofen is not easy to recover; therefore, the FeBTC material composed by magnetite nanoparticles is not suitable for adsorbing ibuprofen. Consequently, it is better to modify the FeBTC by potentiating the pi bond instead of the exposed metallic sites for the physisorption process.

Many efforts are being made to find strategies that increase the stability of pristine MOFs in aqueous media. The incorporation of metallic oxide nanoparticles into MOF made it possible to improve the stability and increase the capacity to remove all contaminants in the present work. The values obtained from removing the three pollutants are promising for functionalized MOF-type materials that are stable in an aqueous medium. The open metal sites, carboxylate functional groups, acid-base properties, and magnetic proprieties of the composite material not only make this material a good candidate for adsorption processes, but it could also be applied in photocatalysis, organic catalysis, electrocatalysis, gas storage, supercapacitors, etc.

\section{Supplementary Materials:}

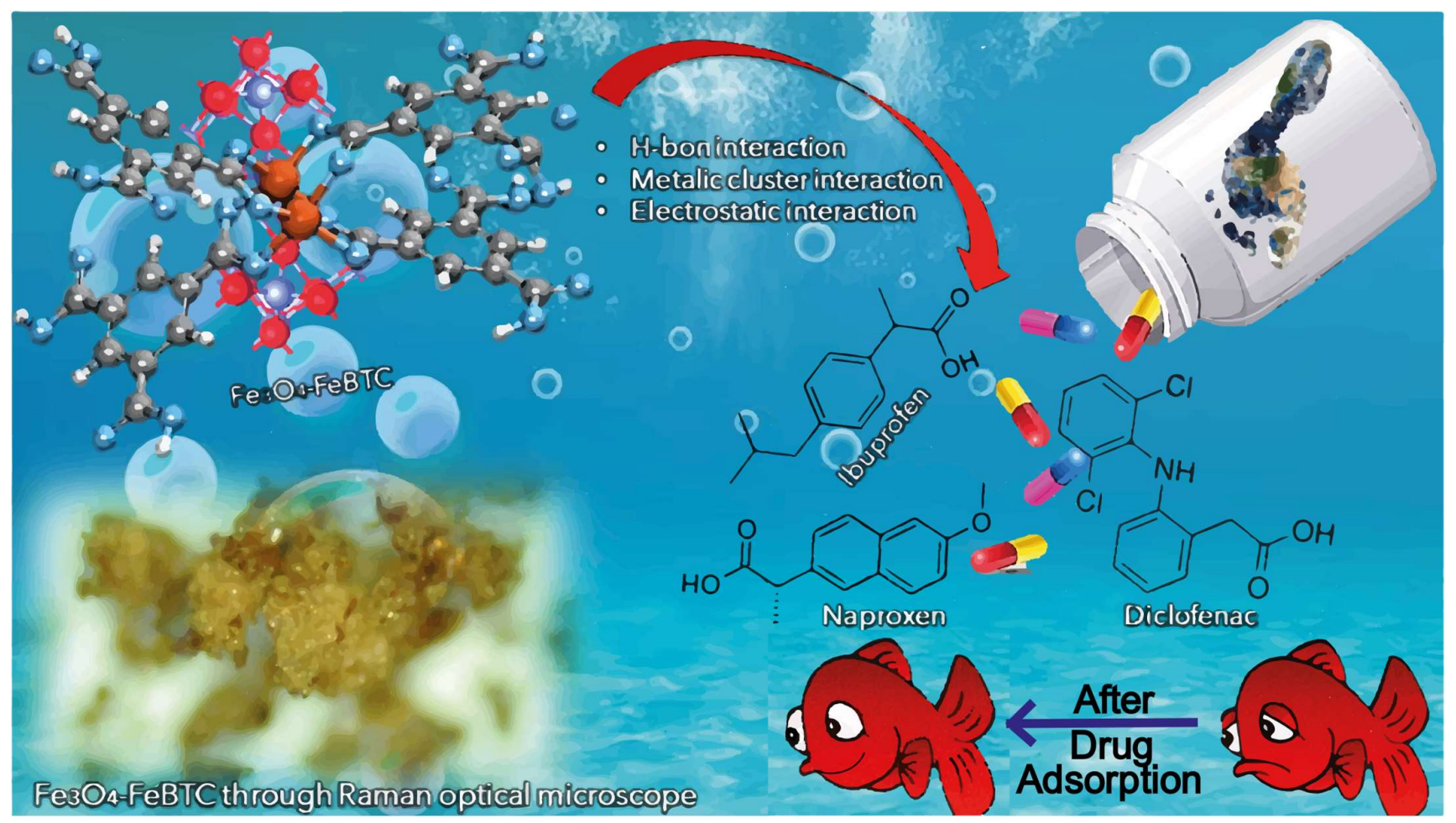


Figure S1. $\mathrm{Fe}_{3} \mathrm{O}_{4}-\mathrm{FeBTC}$ MOF being used to remove diclofenac sodium, naproxen sodium, and ibuprofen from waterinset shows a view through a Raman microscope.

The magnetite diffraction pattern (Figure S2) shows seven main reflections, $2 \theta=19,30$, $36,44,54,57$, and $63^{\circ}$, corresponding to planes (220), (311), (400), (422), (511), and (440), respectively, associated with a simple cubic system of Fd-3m spatial group (JCPDS PDF190629). The average crystallite size of magnetite was $19.3 \mathrm{~nm}$, which was calculated using the Scherrer equation.

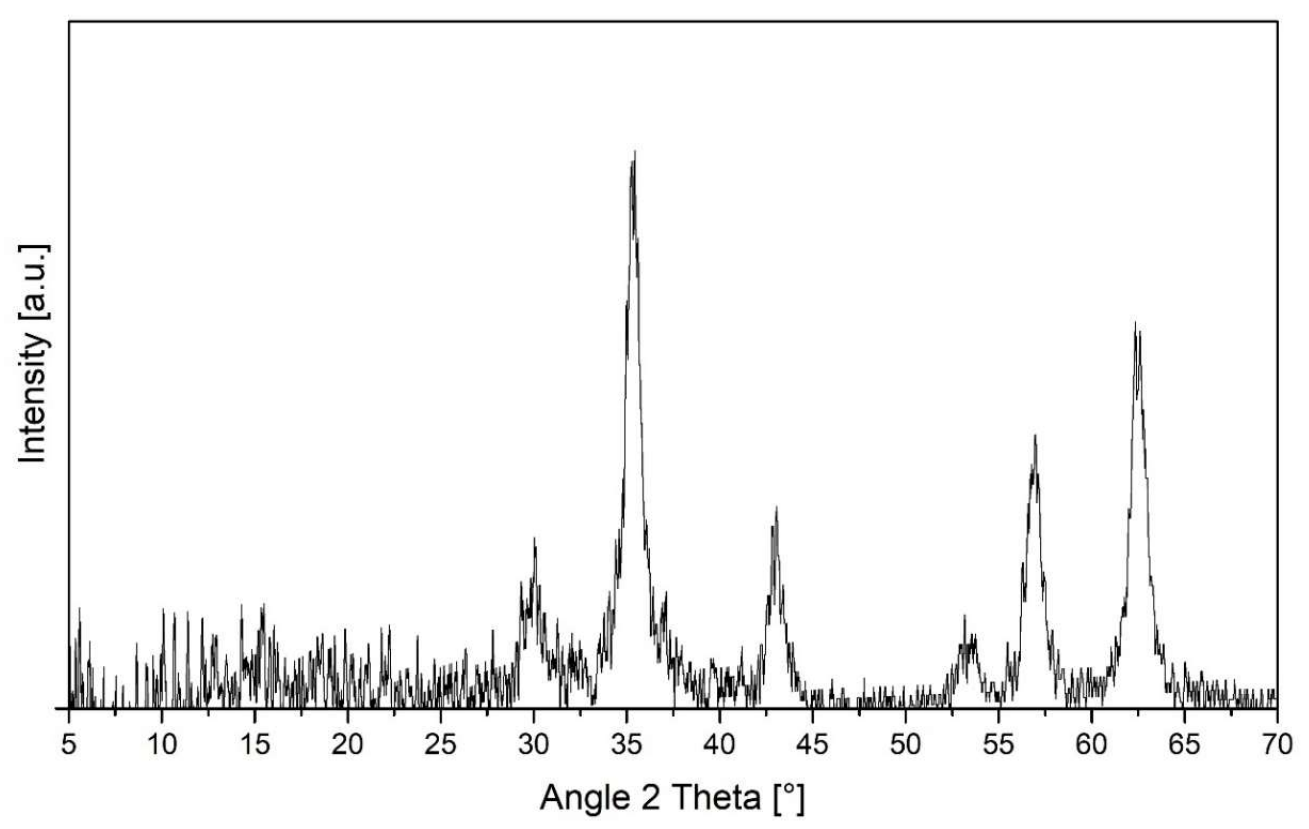

Figure S2. XRD patterns of magnetite nanoparticles.

In the most representative magnetite band, it is possible to see a sharp peak at about 570 $\mathrm{cm}^{-1}$ (Figure S3) characteristic of Fe-O bond absorption. The maximum band presence at $3500 \mathrm{~cm}^{-1}$ is typical of $\mathrm{H}-\mathrm{O}$ bonds, which is related to the humidity of the material. The stretching vibration of the $\mathrm{C}-\mathrm{O}$ bond at $1600^{-1}$ is characteristic of small impurities from ethylene glycol. 


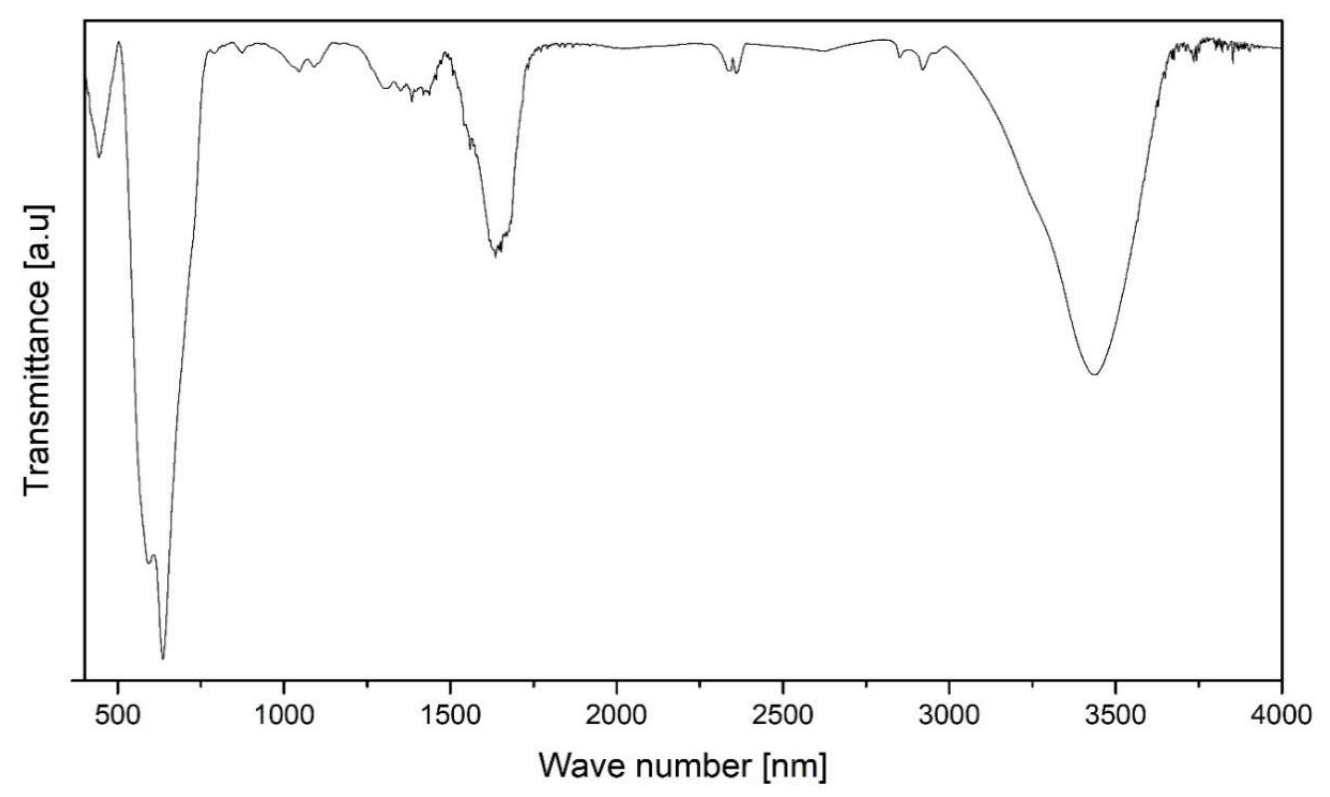

Figure S3. Fourier transform infrared spectroscopy spectra of magnetite.

The results of Raman spectroscopy (Figure S4) show the spectrum characteristics of magnetite nanoparticles, where the maximum band located at $661 \mathrm{~cm}^{-1}$ refers to the modes of vibration stretching of oxygen bound with iron (II) and (III) along the entire crystal lattice. The second most important band is located at $310 \mathrm{~cm}^{-1}$, and the ones located below 500 $\mathrm{cm}^{-1}$ are represented by the phononic activity caused by the dispersion of light after polarization of the material.

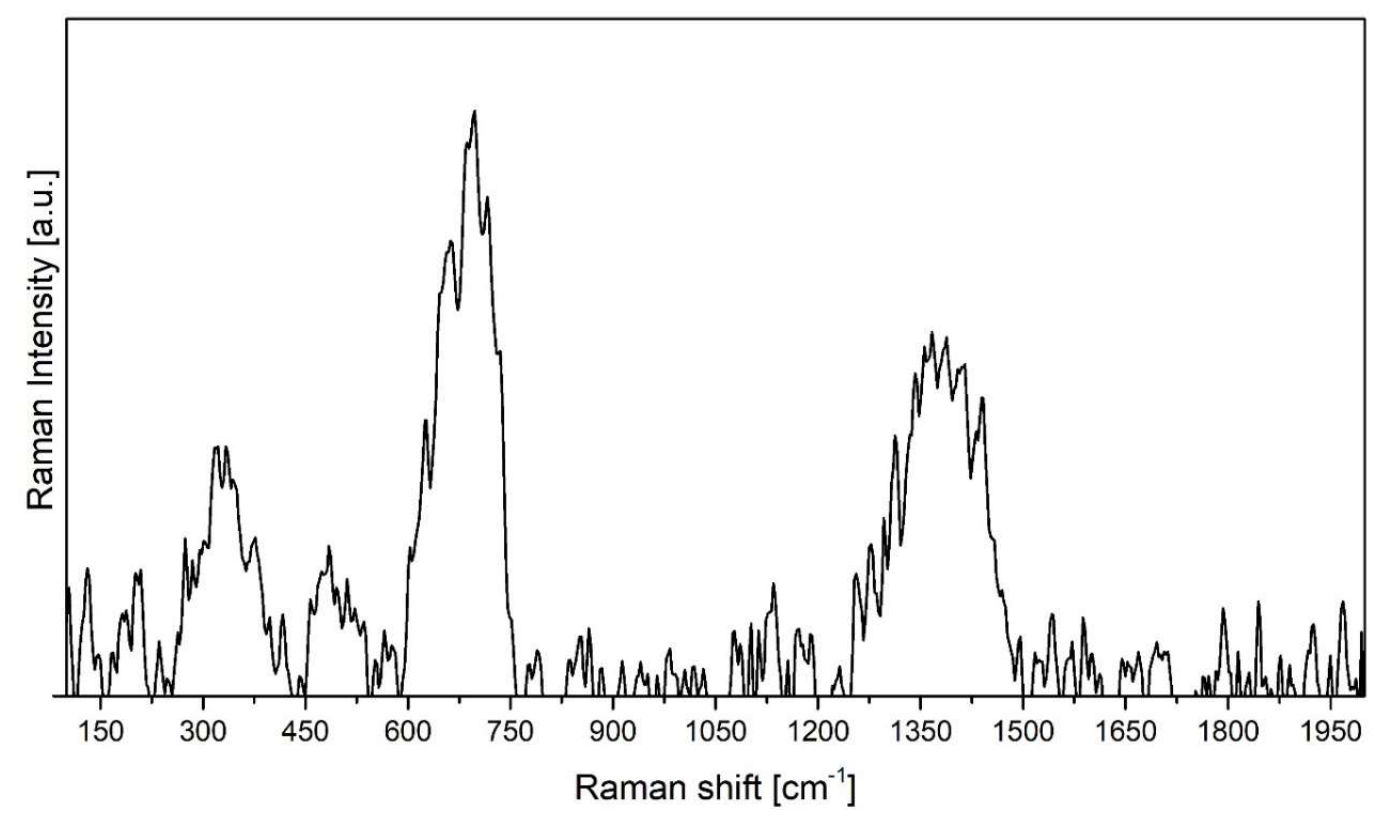

Figure S4. Raman spectra of magnetite. 
Figure S5 shows the materials through a Raman microscope. The images do not show strong differences between $\mathrm{FeBTC}$ and $\mathrm{Fe}_{3} \mathrm{O}_{4}-\mathrm{FeBTC}$ with regard to superficial morphology.

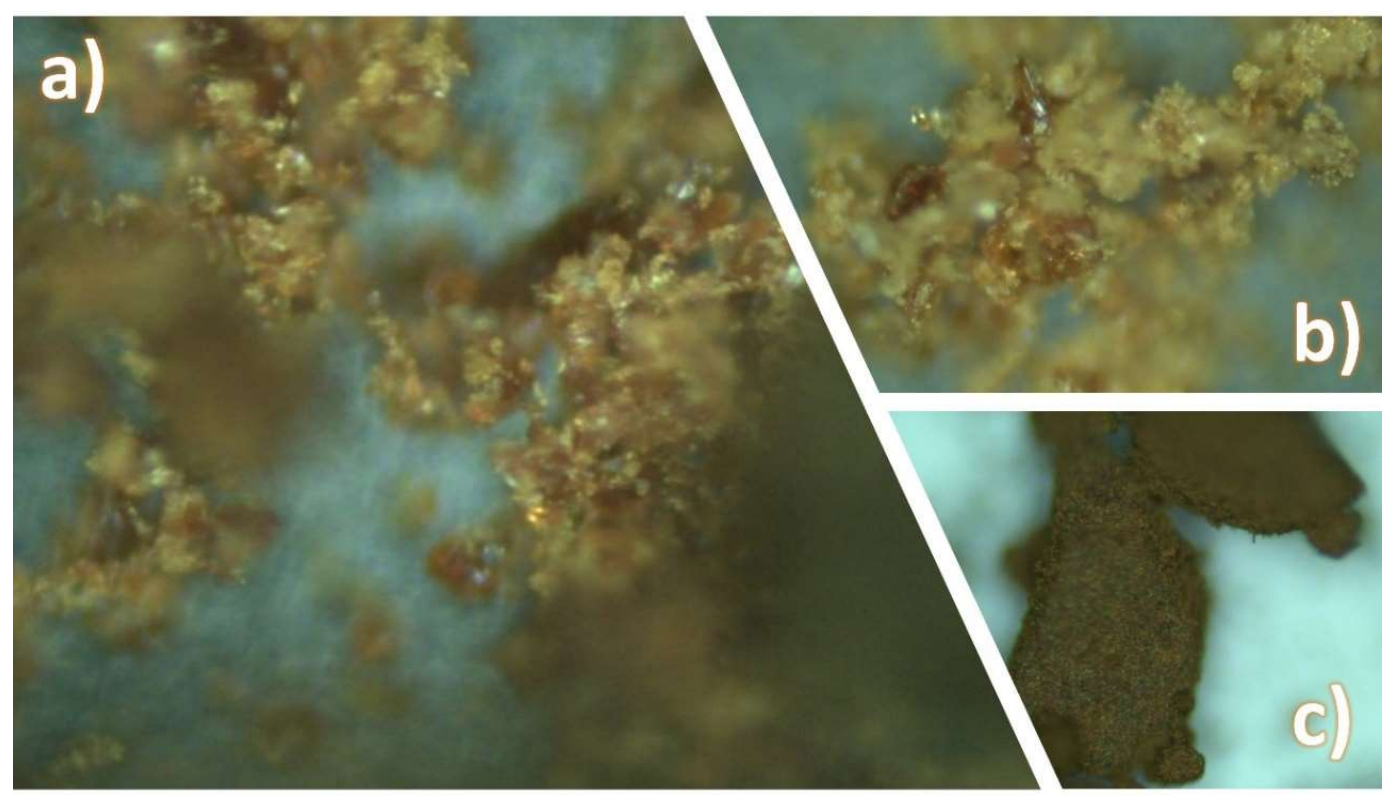

Figure S5. Raman micrographs of (a) $\mathrm{Fe}_{3} \mathrm{O}_{4}-\mathrm{FeBTC}$, (b) FeBTC, and (c) magnetite.

Scanning electron microscopy (Figure S6) was performed to obtain information on the morphology of the particles and the apparent size of their average particle. The FeBTC observed in Figure $6 \mathrm{a}-\mathrm{c}$ presents particles that tend to form bars and cubes, with a nonhomogeneous and very well defined population typical of this material, which was referred to in previous works.

Characterization by EDS was carried out with the aim of corroborating the presence of representative elements of the material, and although this study was merely semi-quantitative, it gives us an approximate idea of the proportion of elements present in the material, which we can compare with respect to the stoichiometry. In the case of FeBTC, only the elements that are part of the $\mathrm{MOF}(\mathrm{Fe}, \mathrm{O}$, and $\mathrm{C}$ ) with some impurities below $1 \%$ are presented, which adjust quite well to the stoichiometry of the material after three regions of the material were explored. 


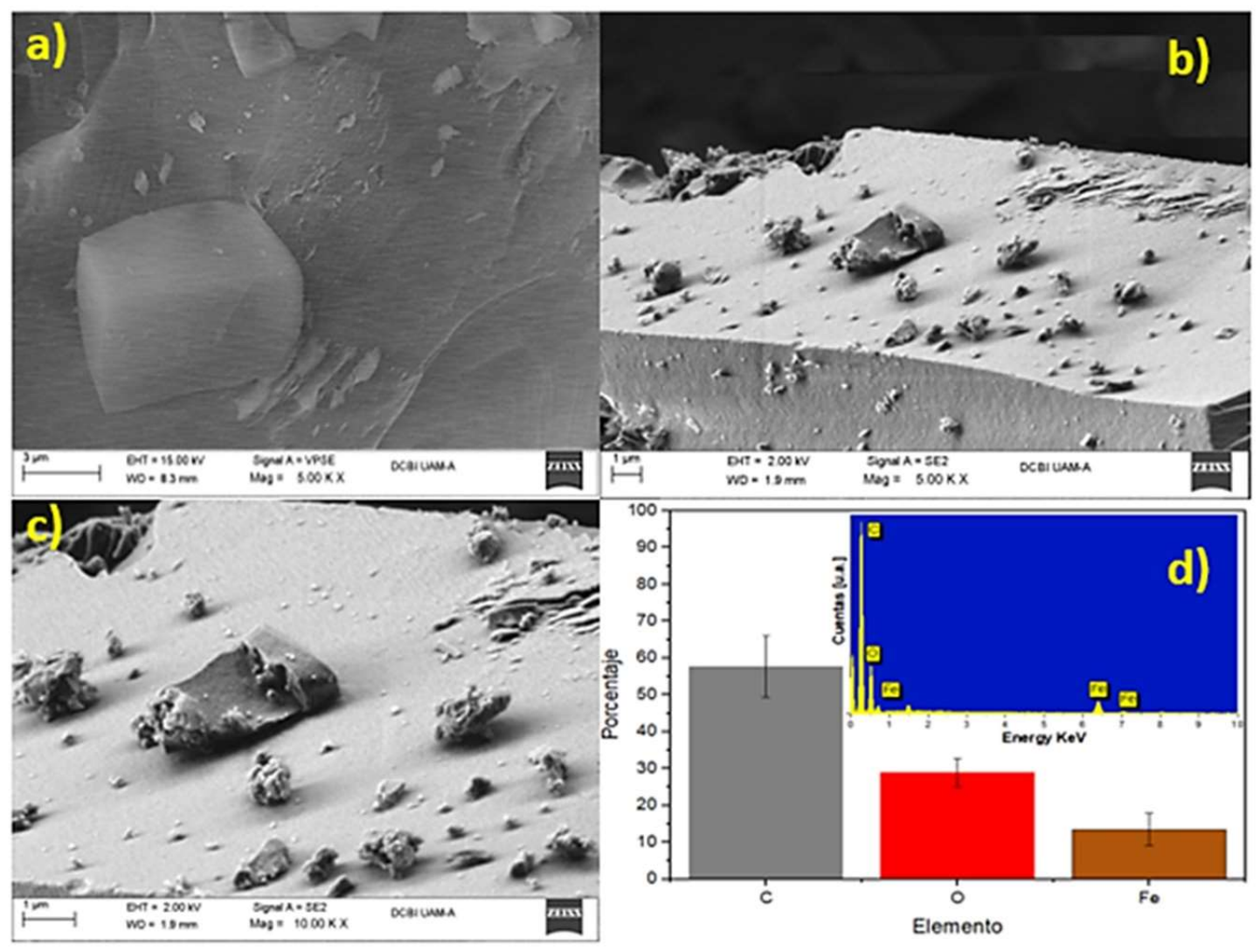

Figure S6. Scanning electron microscopy of FeBTC: (a) scanning at $5 \mathrm{Kx}$ by variable pressure, (b) scanning at $5 \mathrm{kx}$ with secondary electrons, (c) scanning at $10 \mathrm{kx}$ with secondary electrons, and (d) by dispersive energy (results).

Scanning electron microscopy of the $\mathrm{Fe}_{3} \mathrm{O}_{4}-\mathrm{FeBTC}$ composite MOF (Figure S7) shows the presence of particles that tend to form bars; like the FeBTC MOF in its pristine state, they do not have a well-defined morphology or a specific size (Figure S6a-c). On the other hand, EDS characterization shows small increases in the populations of oxygens and irons, which is justified by the presence of magnetite (Figure S6d). 


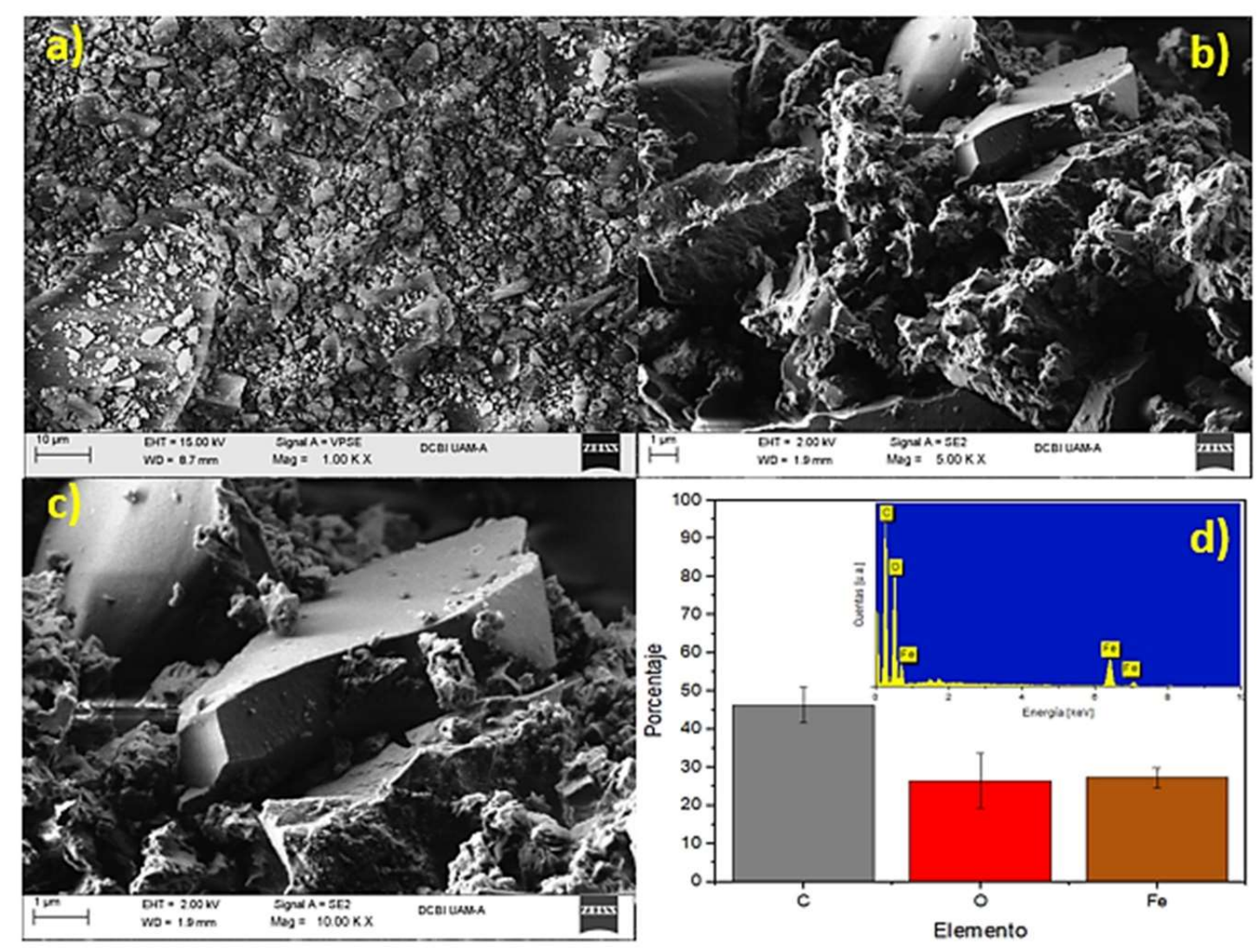

Figure S7. Scanning electron microscopy of $\mathrm{Fe}_{3} \mathrm{O}_{4}-\mathrm{BTC}$ : (a) scanning at $5 \mathrm{Kx}$ by variable pressure, (b) scanning at $5 \mathrm{kx}$ with secondary electrons, (c) scanning at $10 \mathrm{kx}$ with secondary electrons, and (d) by dispersive energy (results).

The thermal stability of the materials was evaluated by means of in situ Raman spectroscopy using a Linkam cell reactor (Figure S8). The procedure consisted of increasing the temperature until the decomposition temperature of MOF with nitrogen flow as treatment gas. The results reveal that the band to $500 \mathrm{~cm}^{-1}$ corresponding to $\mathrm{Fe}-\mathrm{O}$ vibrations tended to disappear with increasing temperature.

The incorporation of magnetite provided FeBTC with greater stability (to $523 \mathrm{~K}, 30 \mathrm{~K}$ more than FeBTC), because - as the characterization by this same technique shows - the magnetite was incorporated in the most vulnerable sites of the MOF, in such a way that it could reinforce the structure (Figure S8). 


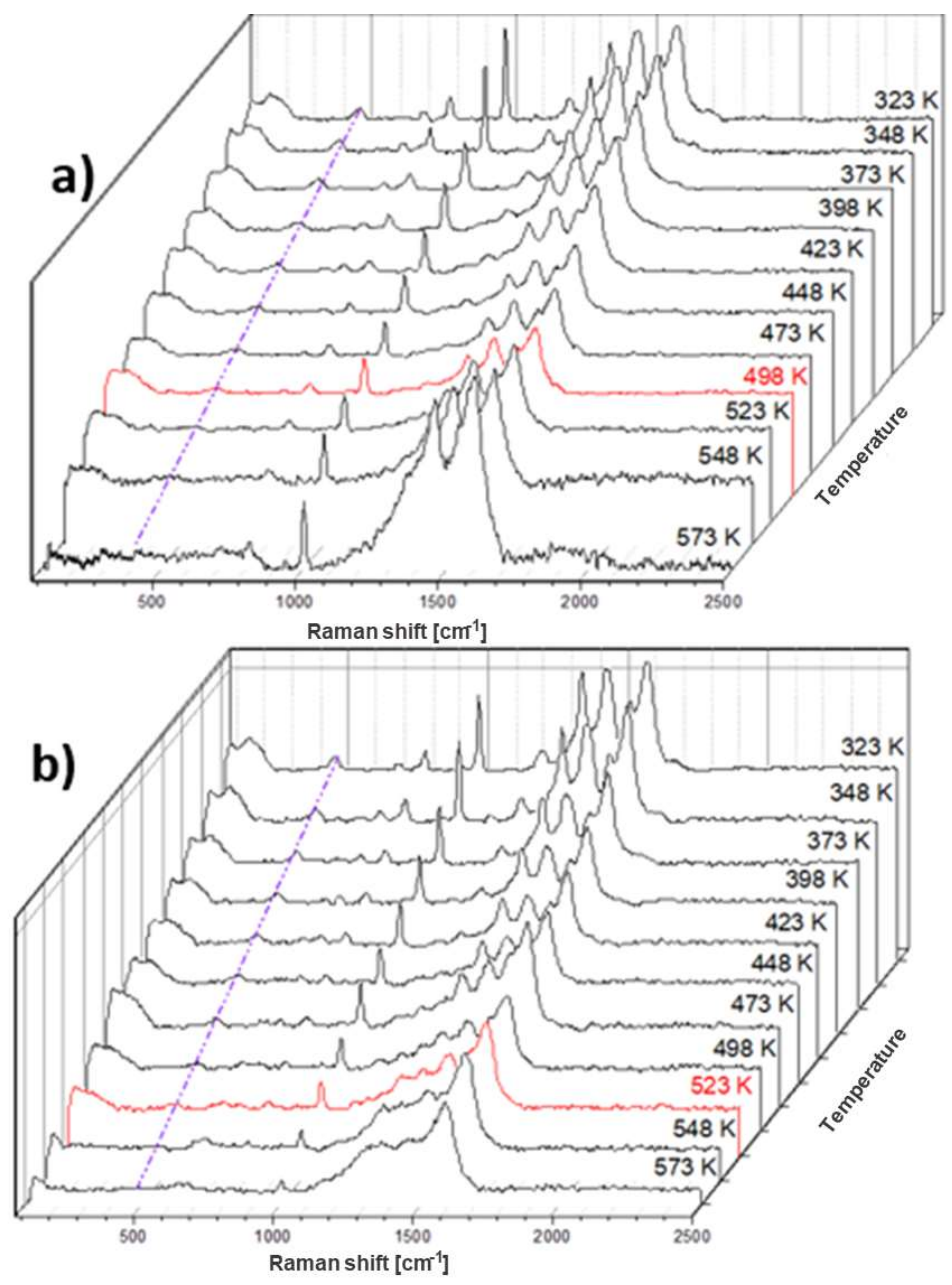

Figure S8. Thermal stability followed by on-site Raman spectroscopy of (a) FeBTC and (b) $\mathrm{Fe}_{3} \mathrm{O}_{4}$-FeBTC.

Characterization by infrared (Figure S9) after the adsorption process shows that there was no change in the functional groups that compose either of the two materials, since the various characteristics of each material are present and well defined. 


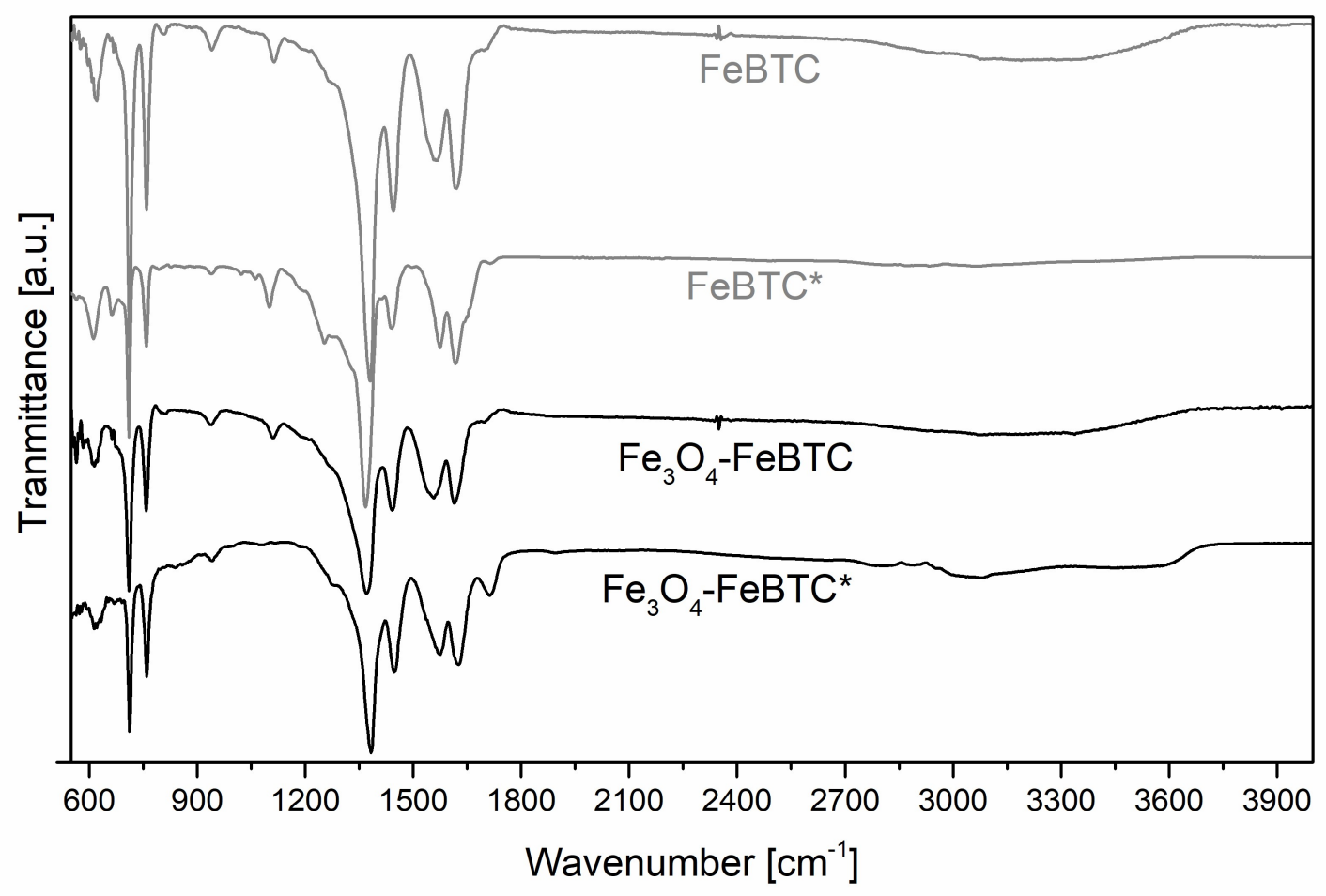

Figure S9. Infrared spectra of materials in their pristine state and after adsorption process with pollutants.

Author Contributions: Conceptualization, methodology, formal analysis, investigation, and writing-original draft preparation, Aldo A. Castañeda Ramírez; visualization, Elizabeth Rojas García; visualization, Ricardo López Medina; resources, writing — review and editing, José L. Contreras Larios; resources, writing - review and editing, Raúl Suarez Parra; supervision, project administration, resources, writing - review and editing, Ana M. Maubert Franco.

Funding: This research was funded by Consejo Nacional de Ciencia y Tecnología (CONACyT), Mexico, through program 001379.

\section{Acknowledgments:}

The authors are especially grateful to Universidad Autónoma Metropolitana Azcapotzalco for accepting Aldo A. Castañeda Ramírez for postgraduate studies.

The authors give special thanks to the PAPIIT IN102216 project.

Conflicts of Interest: The authors declare no conflict of interest. The funders had no role in the design of the study; in the collection, analyses, or interpretation of data; in the writing of the manuscript, or in the decision to publish the results.

\section{References}

1. Wang, J.; Wang, S. Removal of Pharmaceuticals and Personal Care Products (PPCPs) from Wastewater: A Review. Journal of Environmental Management. Academic Press November. 2016, 1, pp 620-640. https://doi.org/10.1016/j.jenvman.2016.07.049.

2. Shailendra Mudgal, A.; De Toni, A.; Shailendra Mudgal, O.; Wiberg, O. Study on the Environmental Risks of Medicinal Products, Final Report Prepared for Executive Agency for Health and Consumers Photo Credit: Cover @ Per; 2013. 
3. Wang, Q.; Shaheen, S. M.; Jiang, Y.; Li, R.; Slaný, M.; Abdelrahman, H.; Kwon, E.; Bolan, N.; Rinklebe, J.; Zhang, Z. Fe/Mnand P-Modified Drinking Water Treatment Residuals Reduced $\mathrm{Cu}$ and Pb Phytoavailability and Uptake in a Mining Soil. J. Hazard. Mater. 2021, 403, 123628. https://doi.org/10.1016/j.jhazmat.2020.123628.

4. Sharma, S.; Bhattacharya, A. Drinking Water Contamination and Treatment Techniques. Appl. Water Sci. 2017, 7, 10431067. https://doi.org/10.1007/s13201-016-0455-7.

5. Batten, S. R.; Champness, N. R.; Chen, X.-M.; Garcia-Martinez, J.; Kitagawa, S.; Öhrström, L.; O’Keeffe, M.; Paik Suh, M.; Reedijk, J. Terminology of Metal-Organic Frameworks and Coordination Polymers (IUPAC Recommendations 2013). Pure Appl. Chem. 2013, 85 (8), 1715-1724. https://doi.org/10.1351/PAC-REC-12-11-20.

6. Khan, N. A.; Jhung, S. H. Synthesis of Metal-Organic Frameworks (MOFs) with Microwave or Ultrasound: Rapid Reaction, Phase-Selectivity, and Size Reduction. Coord. Chem. Rev. 2015, 285, 11-23. https://doi.org/10.1016/j.ccr.2014.10.008.

7. Dhakshinamoorthy, A.; Alvaro, M.; Horcajada, P.; Gibson, E.; Vishnuvarthan, M.; Vimont, A.; Grenèche, J.-M.; Serre, C.; Daturi, M.; Garcia, H. Comparison of Porous Iron Trimesates Basolite F300 and MIL-100(Fe) As Heterogeneous Catalysts for Lewis Acid and Oxidation Reactions: Roles of Structural Defects and Stability. ACS Catal. 2012, 2 (10), $2060-2065$. https://doi.org/10.1021/cs300345b.

8. Shahid, S.; Nijmeijer, K. High Pressure Gas Separation Performance of Mixed-Matrix Polymer Membranes Containing Mesoporous Fe(BTC). J. Memb. Sci. 2014, 459, 33-44. https://doi.org/10.1016/j.memsci.2014.02.009.

9. Bhadra, B. N.; Ahmed, I.; Kim, S.; Jhung, S. H. Adsorptive Removal of Ibuprofen and Diclofenac from Water Using MetalOrganic Framework-Derived Porous Carbon. Chem. Eng. J. 2017, 314, 50-58. https://doi.org/10.1016/j.cej.2016.12.127.

10. Hasan, Z.; Choi, E.-J.; Jhung, S. H. Adsorption of Naproxen and Clofibric Acid over a Metal-Organic Framework MIL-101 Functionalized with Acidic and Basic Groups. Chem. Eng. J. 2013, 219, 537-544. https://doi.org/10.1016/j.cej.2013.01.002.

11. Petrova, T. M.; Fachikov, L.; Hristov, J. The Magnetite as Adsorbent for Some Hazardous Species from Aqueous Solutions: A Review. 2011, No. May 2014.

12. Markeb, A. A.; Ordosgoitia, L. A.; Alonso, A.; Sánchez, A.; Font, X.; Kim, J.-Y.; Luo, T.; Meng, F.; Jin, Z.; Lin, D.; Shen, W.; Kong, L.; Liu, J. Novel Magnetic Core-Shell Ce-Ti@Fe 3 O 4 Nanoparticles as an Adsorbent for Water Contaminants Removal. RSC Adv. 2016, 6 (62), 56913-56917. https://doi.org/10.1039/C6RA12144F.

13. Zhang, T.; Zhang, X.; Yan, X.; Kong, L.; Zhang, G.; Liu, H.; Qiu, J.; Yeung, K. L. Synthesis of Fe3O4@ZIF-8 Magnetic CoreShell Microspheres and Their Potential Application in a Capillary Microreactor. Chem. Eng. J. 2013, 228, 398-404. https://doi.org/10.1016/j.cej.2013.05.020.

14. Chen, G.; Yu, B.; Lu, C.; Zhang, H.; Shen, Y.; Cong, H. Controlled Synthesis of Fe3O4@ZIF-8 Nanoparticles for Drug Delivery. CrystEngComm 2018, 20 (46), 7486-7491. https://doi.org/10.1039/c8ce01302k.

15. Pang, F.; He, M.; Ge, J. Controlled Synthesis of Fe 3 O 4 /ZIF-8 Nanoparticles for Magnetically Separable Nanocatalysts. Chem. - A Eur. J. 2015, 21 (18), 6879-6887. https://doi.org/10.1002/chem.201405921.

16. Min, X.; Yang, W.; Hui, Y. F.; Gao, C. Y.; Dang, S.; Sun, Z. M. Fe3O4@ZIF-8: A Magnetic Nanocomposite for Highly Efficient UO22+ Adsorption and Selective UO22+/Ln3+ Separation. Chem. Commun. 2017, 53 (30), 4199-4202. https://doi.org/10.1039/c6cc10274c.

17. Zhao, X.; Liu, S.; Tang, Z.; Niu, H.; Cai, Y.; Meng, W.; Wu, F.; Giesy, J. P. Synthesis of Magnetic Metal-Organic Framework (MOF) for Efficient Removal of Organic Dyes from Water. Sci. Rep. 2015, 5 (1), 1-10. https://doi.org/10.1038/srep11849.

18. Liu, H.; Ren, X.; Chen, L. Synthesis and Characterization of Magnetic Metal-Organic Framework for the Adsorptive Removal of Rhodamine B from Aqueous Solution. J. Ind. Eng. Chem. 2016, 34, 278-285.

https://doi.org/10.1016/j.jiec.2015.11.020. 
19. Liu, S.; Zhao, Y.; Wang, T.; Liang, N.; Hou, X. Core-Shell Fe3O4@MIL-100(Fe) Magnetic Nanoparticle for Effective Removal of Meloxicam and Naproxen in Aqueous Solution. J. Chem. Eng. Data 2019, 64 (7), 2997-3007. https://doi.org/10.1021/acs.jced.9b00061.

20. Li, S.; Cui, J.; Wu, X.; Zhang, X.; Hu, Q.; Hou, X. Rapid in Situ Microwave Synthesis of Fe3O4@MIL-100(Fe) for Aqueous Diclofenac Sodium Removal through Integrated Adsorption and Photodegradation. J. Hazard. Mater. 2019, 373, $408-416$. https://doi.org/10.1016/j.jhazmat.2019.03.102.

21. Liu, S.; Zhao, Y.; Wang, T.; Liang, N.; Hou, X. Core-Shell Fe3O4@MIL-100(Fe) Magnetic Nanoparticle for Effective Removal of Meloxicam and Naproxen in Aqueous Solution. J. Chem. Eng. Data 2019, 64 (7), $2997-3007$. https://doi.org/10.1021/acs.jced.9b00061.

22. Li, S.; Cui, J.; Wu, X.; Zhang, X.; Hu, Q.; Hou, X. Rapid in Situ Microwave Synthesis of Fe3O4@MIL-100(Fe) for Aqueous Diclofenac Sodium Removal through Integrated Adsorption and Photodegradation. J. Hazard. Mater. 2019, 373 (January), 408-416. https://doi.org/10.1016/j.jhazmat.2019.03.102.

23. Cai, W.; Guo, M.; Weng, X.; Zhang, W.; Chen, Z. Adsorption of Doxorubicin Hydrochloride on Glutaric Anhydride Functionalized Fe3O4@SiO2 Magnetic Nanoparticles. Mater. Sci. Eng. C 2019, 98, 65-73. https://doi.org/10.1016/j.msec.2018.12.145.

24. Yang, Y.-F.; Meng, F.-Y.; Li, X.-H.; Wu, N.-N.; Deng, Y.-H.; Wei, L.-Y.; Zeng, X.-P. Magnetic Graphene Oxide-Fe 3 O 4 -PANI Nanoparticle Adsorbed Platinum Drugs as Drug Delivery Systems for Cancer Therapy . J. Nanosci. Nanotechnol. 2019, 19 (12), 7517-7525. https://doi.org/10.1166/jnn.2019.16768.

25. Rojas-García, E.; López Medina, R.; May-Lozano, M.; Hernández-Pérez, I.; Hernández Pérez, I.; Valero, M.; Maubert-Franco, A. Adsorption of Azo-Dye Orange II from Aqueous Solutions Using a Metal-Organic Framework Material: Iron- Benzenetricarboxylate. Materials (Basel). 2014, 7 (12), 8037-8057. https://doi.org/10.3390/ma7128037.

26. Castañeda, A. Incorporación de Nanotubos de Carbono en Estructuras Metal-Orgánicas para el Almacenamiento de Hidrógeno, Master-degree, Universidad Autónoma Metropolitana-A, 2017.

27. Liu, H.; Ren, X.; Chen, L. Synthesis and Characterization of Magnetic Metal-Organic Framework for the Adsorptive Removal of Rhodamine B from Aqueous Solution. J. Ind. Eng. Chem. 2016, 34, 278-285. https://doi.org/10.1016/j.jiec.2015.11.020.

28. Jiang, X.; Chen, H.-Y.; Liu, L.-L.; Qiu, L.-G.; Jiang, X. Fe 3 O 4 Embedded ZIF-8 Nanocrystals with Ultra-High Adsorption Capacity towards Hydroquinone. J. Alloys Compd. 2015, 646, 1075-1082. https://doi.org/10.1016/j.jallcom.2015.06.021.

29. Zijlstra, W. G. (Willem G.; Buursma, A.; Assendelft, O. W. van. Visible and near Infrared Absorption Spectra of Human and Animal Haemoglobin : Determination and Application; VSP, 2000.

30. Opanasenko, M.; Dhakshinamoorthy, A.; Čejka, J.; Garcia, H. Deactivation Pathways of the Catalytic Activity of MetalOrganic Frameworks in Condensation Reactions. ChemCatChem 2013, 5 (6), $1553-1561$. https://doi.org/10.1002/cctc.201200643.

31. Ding, J.; Tao, K.; Li, J.; Song, S.; Sun, K. Cell-Specific Cytotoxicity of Dextran-Stabilized Magnetite Nanoparticles. Colloids Surfaces B Biointerfaces 2010, 79 (1), 184-190. https://doi.org/10.1016/j.colsurfb.2010.03.053.

32. Songvorawit, N.; Tuitemwong, K.; Tuitemwong, P. Single Step Synthesis of Amino-Functionalized Magnetic Nanoparticles with Polyol Technique at Low Temperature. ISRN Nanotechnol. 2011, 1-6. https://doi.org/10.5402/2011/483129.

33. Khalil, M. I. Co-Precipitation in Aqueous Solution Synthesis of Magnetite Nanoparticles Using Iron(III) Salts as Precursors. Arab. J. Chem. 2015, 8 (2), 279-284. https://doi.org/10.1016/j.arabjc.2015.02.008.

34. Slaný, M.; Jankovič, L.; Madejová, J. Structural Characterization of Organo-Montmorillonites Prepared from a Series of Primary 
Alkylamines Salts: Mid-IR and near-IR Study. Appl. Clay Sci. 2019, 176, 11-20. https://doi.org/10.1016/j.clay.2019.04.016.

35. Li, L.; Liu, X. L.; Geng, H. Y.; Hu, B.; Song, G. W.; Xu, Z. S. A MOF/Graphite Oxide Hybrid (MOF: HKUST-1) Material for the Adsorption of Methylene Blue from Aqueous Solution. J. Mater. Chem. A 2013, 1 (35), 10292-10299. https://doi.org/10.1039/C3TA11478C.

36. Skumiel, A.; Józefczak, A.; Timko, M.; Kopčanský, P.; Herchl, F.; Koneracká, M.; Tomašovičová, N. Heating Effect in Biocompatible Magnetic Fluid. Int. J. Thermophys. 2007, 28 (5), 1461-1469. https://doi.org/10.1007/s10765-006-0138-y.

37. Sundman, A.; Byrne, J. M.; Bauer, I.; Menguy, N.; Kappler, A. Interactions between Magnetite and Humic Substances: Redox Reactions and Dissolution Processes. Geochem. Trans. 2017, 18 (1), 1-12. https://doi.org/10.1186/s12932-017-0044-1.

38. Huo, J. B.; Xu, L.; Yang, J. C. E.; Cui, H. J.; Yuan, B.; Fu, M. L. Magnetic Responsive Fe3O4-ZIF-8 Core-Shell Composites for Efficient Removal of As(III) from Water. Colloids Surfaces A Physicochem. Eng. Asp. 2018, 539, 59-68. https://doi.org/10.1016/j.colsurfa.2017.12.010.

39. Prestipino, C.; Regli, L.; Vitillo, J. G.; Bonino, F.; Damin, A.; Lamberti, C.; Zecchina, A.; Solari, P. L.; Kongshaug, K. O.; Bordiga, S. Local Structure of Framework Cu(II) in HKUST-1 Metallorganic Framework: Spectroscopic Characterization upon Activation and Interaction with Adsorbates. Chem. Mater. 2006, 18 (5), 1337-1346. https://doi.org/10.1021/cm052191g

40. Kim, H. K.; Yun, W. S.; Kim, M.; Kim, J. Y.; Bae, Y.; Lee, J.; Jeong, N. C. A Chemical Route to Activation of Open Metal Sites in the Copper- Based Metal - Organic Framework Materials HKUST - 1 and Cu-MOF - 2. 2015, 222 (i), 1-8. https://doi.org/10.1021/jacs.5b06637.

41. Thommes, M.; Kaneko, K.; Neimark, A. V.; Olivier, J. P.; Rodriguez-Reinoso, F.; Rouquerol, J.; Sing, K. S. W. Physisorption of Gases, with Special Reference to the Evaluation of Surface Area and Pore Size Distribution (IUPAC Technical Report). Pure Appl. Chem. 2015, 87 (9-10), 1051-1069. https://doi.org/10.1515/pac-2014-1117.

42. Gasparov, L. V.; Tanner, D. B.; Romero, D. B.; Berger, H.; Margaritondo, G.; Forró, L. Infrared and Raman Studies of the Verwey Transition in Magnetite. Phys. Rev. B - Condens. Matter Mater. Phys. 2000, 62 (12), $7939-7944$. https://doi.org/10.1103/PhysRevB.62.7939.

43. Li, J.; Liu, Y.; Wang, X.; Zhao, G.; Ai, Y.; Han, B.; Wen, T.; Hayat, T.; Alsaedi, A.; Wang, X. Experimental and Theoretical Study on Selenate Uptake to Zirconium Metal-Organic Frameworks: Effect of Defects and Ligands. Chem. Eng. J. 2017, 330, 1012-1021. https://doi.org/10.1016/j.cej.2017.08.038.

44. Zhang, C.; Han, C.; Sholl, D. S.; Schmidt, J. R. Computational Characterization of Defects in Metal-Organic Frameworks: Spontaneous and Water-Induced Point Defects in ZIF-8. J. Phys. Chem. Lett. 2016, 7 (3), $459-464$. https://doi.org/10.1021/acs.jpclett.5b02683.

45. De Franco, M. A. E.; de Carvalho, C. B.; Bonetto, M. M.; de Pelegrini Soares, R.; Féris, L. A. Diclofenac Removal from Water by Adsorption Using Activated Carbon in Batch Mode and Fixed-Bed Column: Isotherms, Thermodynamic Study and Breakthrough Curves Modeling. J. Clean. Prod. 2018, 181, 145-154. https://doi.org/10.1016/j.jclepro.2018.01.138.

46. Inglezakis, V. J.; Zorpas, A. A. Heat of Adsorption, Adsorption Energy and Activation Energy in Adsorption and Ion Exchange Systems. Desalin. Water Treat. 2012, 39 (1-3), 149-157. https://doi.org/10.1080/19443994.2012.669169.

47. Huang, M.; Xiang, W.; Zhou, T.; Mao, J.; Wu, X.; Guo, X. The Critical Role of the Surface Iron-Oxalate Complexing Species in Determining Photochemical Degradation of Norfloxacin Using Different Iron Oxides. Sci. Total Environ. 2019, 697, 134220. https://doi.org/10.1016/j.scitotenv.2019.134220. 